\title{
Cost-effective Semiconductor Technologies for RF and Microwave Applications
}

\author{
Christopher Snowden \\ Vice-Chancellor and Chief Executive, \\ University of Surrey, UK
}




\section{RF Markets \& Applications}

Communications Security and Defence Transport

Health

Community/monitoring Education and Entertainment

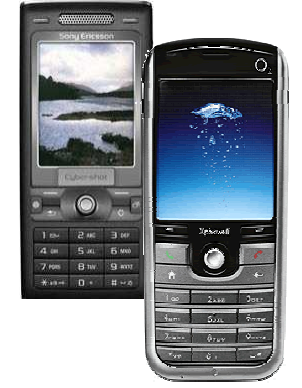

Mobile Phones

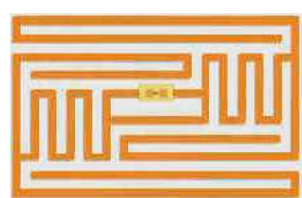

RFID

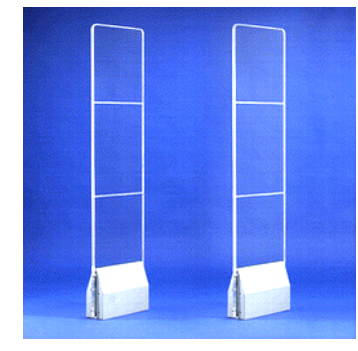

Security

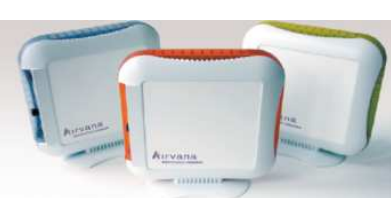

Femtocells

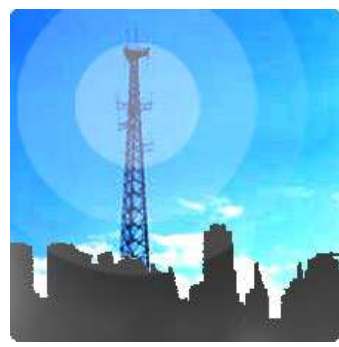

Wireless Infrastructure

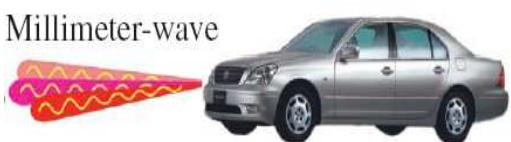

Automotive Radar
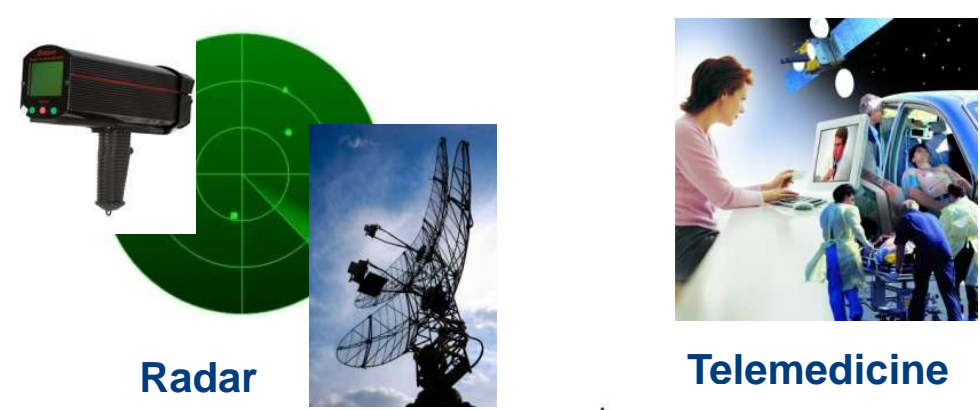

Telemedicine

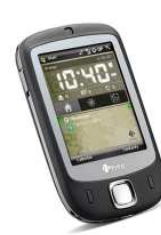

Mobile WLAN

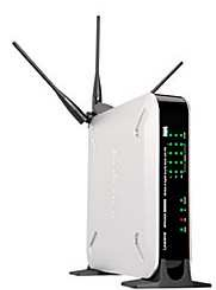

WLAN
Wireless

WPAN 


\section{Semiconductors for RF}

- Silicon (Si): Bipolar, CMOS, BiCMOS, LDMOS

- Gallium Arsenide (GaAs): pHEMT, MESFET HBT, mHemt, BiFET

- Indium Phosphide (InP): pHEMT, HBT

- Silicon-Germanium (SiGe): HBT

- Gallium Nitride (GaN): HEMT, MOSFET

- Superior mixed signal integration capabilities in Si.

- Supplied by IDMs or Foundries - mostly to OEMs.

- Integrated device manufacturers supplying components and modules

- Foundry services providing finished wafers

- \$255 Billion market for semiconductors in $2008^{1}$

- \$3Bn GaAs MMIC Market with \$220M in Foundry Business ${ }^{2}$

- Technology drivers for lower cost, higher functionality and higher speed/frequencies of operation

- Millimetre-wave opportunities for compound semiconductors and SiGe. 


\section{"Junction for the Function"”}

\section{The choice of semiconductor is based on:}

- Cost - design \& production

- Performance - electronic, reliability

- Process yield and consistency

- Integration - power and functionality/\$

- Availability, capacity and delivery time

The final choice of semiconductor technology will depend on the application but only the right combination of all parameters will provide the optimum solution at the right cost. 


\section{Cost/function \& Performance}

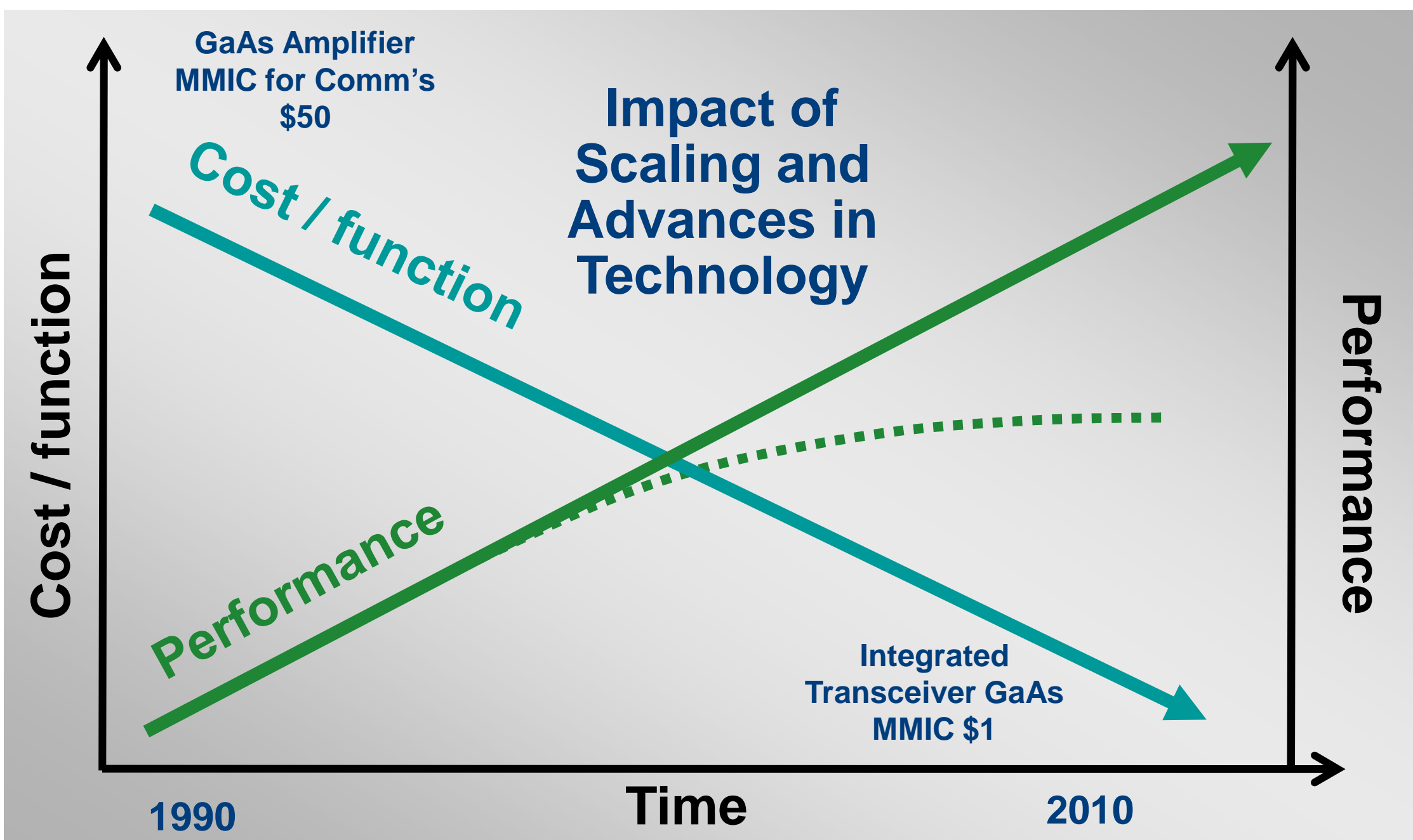

Adapted from C. Claeys, IMEC 


\section{RF Semiconductor Technologies}

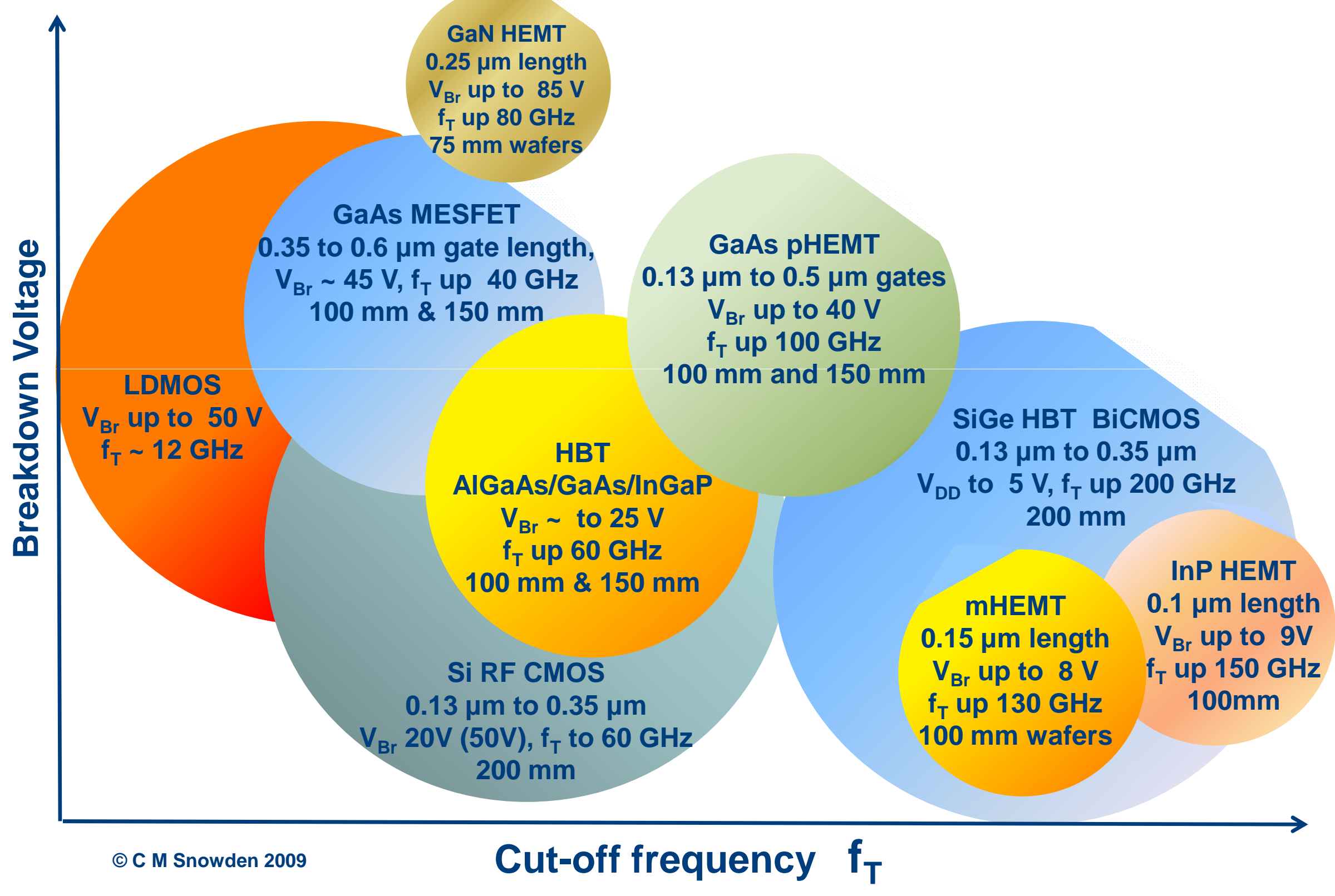




\section{Technology Cost Drivers}

- Increasing design cost for decreasing gate length in Si.

- Mask set costs in silicon vary from $\$ 100 \mathrm{k}$ to $\$ 1 \mathrm{~m}$ as the gate length shrinks from $0.18 \mu \mathrm{m}$ down to $65 \mathrm{~nm}$.

- RF Si CMOS and SiGe are cost-efficient in very high volumes.

- Mask sets for GaAs typically cost $\$ 25 k$ to $\$ 50 k$.

- Design Iterations take typically longer in silicon (8 weeks).

- GaAs hot-lot cycle times typically 4 weeks

- GaAs is still the technology of choice for RF power and switching in cellular and WLAN markets

- GaAs offers better power efficiency

- GaAs costs continue to fall and yields are high in $150 \mathrm{~mm}$.

- GaAs offers high levels of integration with E/D pHEMT, BiHEMT

- Wafer Cost: $\$ 1000$ (CMOS) $\$ 2500$ (SiGe); GaAs $\$ 1000$ to $\$ 2500$...... ..... + design + masks. 


\section{Si RF CMOS}

- RF CMOS is well suited to high levels of integration and System on Chip solutions (SoC) using $200 \mathrm{~mm}$ wafer technology for high volume markets.

- High volume CMOS transceiver circuits, low-Noise amplifiers, PLL, prescalers, VCOs and synthesizers - typically to $3 \mathrm{GHz}$ (demonstrated up to $104 \mathrm{GHz}$ ).

- RF switches, including SP6T and SP9T for cellular handsets, with insertion loss of $<0.6 \mathrm{DB}$ and isolation of better than $39 \mathrm{~dB}$.

- Bluetooth can be fabricated and implemented using CMOS because of the low powers involved and well suited to very high volumes.

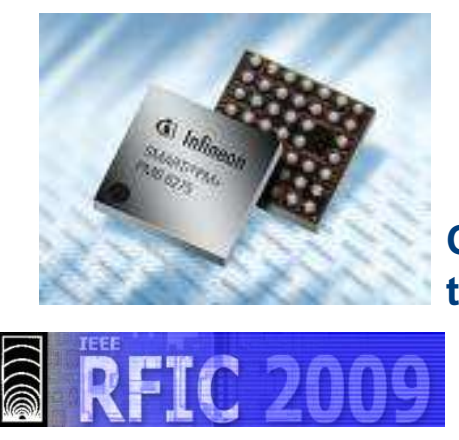

Flip-Chip SP6T and SP7T RF switches (Peregrine Semiconductor)

Quadband RF CMOS transceiver (Infineon)

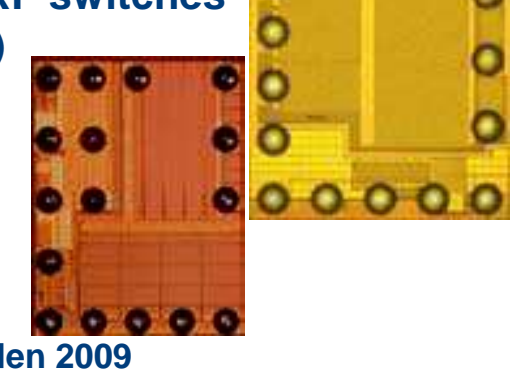

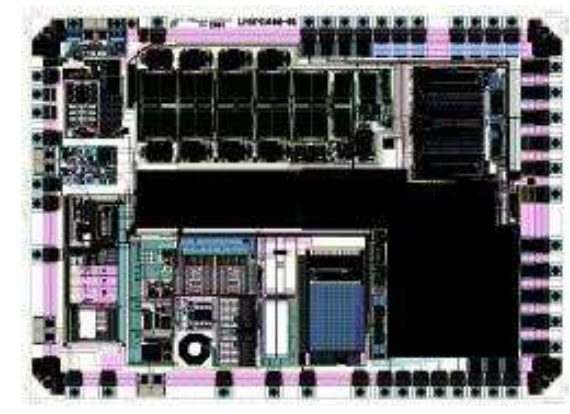

RF CMOS transceiver, over 500 million shipped 1.9 to $2.4 \mathrm{GHz}$ (Plextek + National Semiconductor)

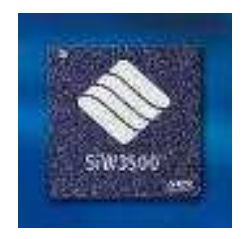

Bluetooth (Ferret)

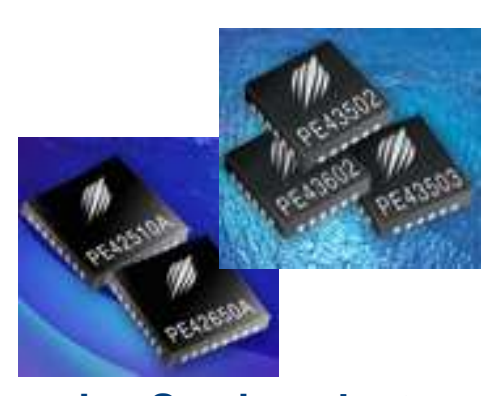

Peregrine Semiconductor $\mathrm{RF}$ switches and attenuators 


\section{RF CMOS for Wireless PAs}

- Biggest issue with CMOS for RF applications is the low breakdown voltage, requiring very challenging impedance transformation for high output power levels and careful handling of mismatch (e.g. from cellular phone antennas).

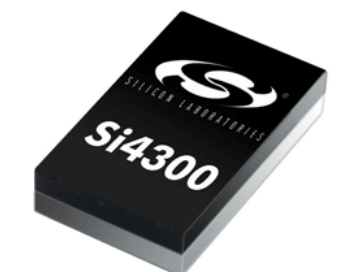

Silicon Laboratories Si4300 GSM/GPRS PA

- Until recently, CMOS power amplifiers were not suitable for cellular phones PAs (GaAs domination).

- New developments in device and circuit technologies show the potential for CMOS power amplifiers for massmarket applications.

- The largest challenges faced by CMOS for PA design remain in terms of output power, mismatch handling, and thermal management.

- IBM have 50V breakdown voltage $180 \mathrm{~nm}$ RF process.

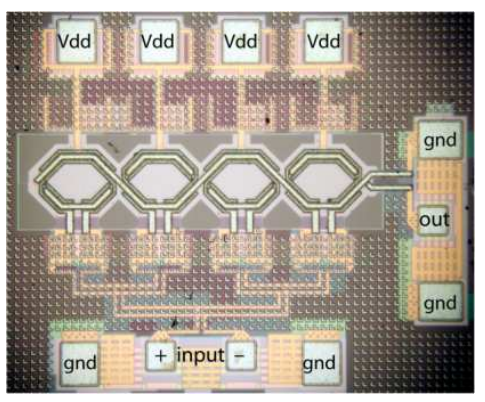

Workshop: WSA (RFIC 2009) "Advances in CMOS

5.8 GHz 1V CMOS PA (2007 RF Power Amplifiers for Cellular ...."

RFIC Best Student Paper), Haldi, Berkeley 


\section{SiGe BiCMOS Technology}

- SiGe established as a low voltage high performance technology for RF through to millimetre-wave with $\mathrm{f}_{\mathrm{T}}$ 's as high as $200 \mathrm{GHz}$.

- Mask set costs make this best suited to high volume applications.

- $0.13 \mu \mathrm{m}, 0.18 \mu \mathrm{m} \& 0.35 \mu \mathrm{m}$ CMOS gate lengths and SiGe bipolar transistor (SiGe BiCMOS ) with supply voltages of 1.8 or $3.3 \mathrm{~V}$.

- Suitable for RF to mm-wave applications.

- Normally PA's and LNA/PA filters off-chip

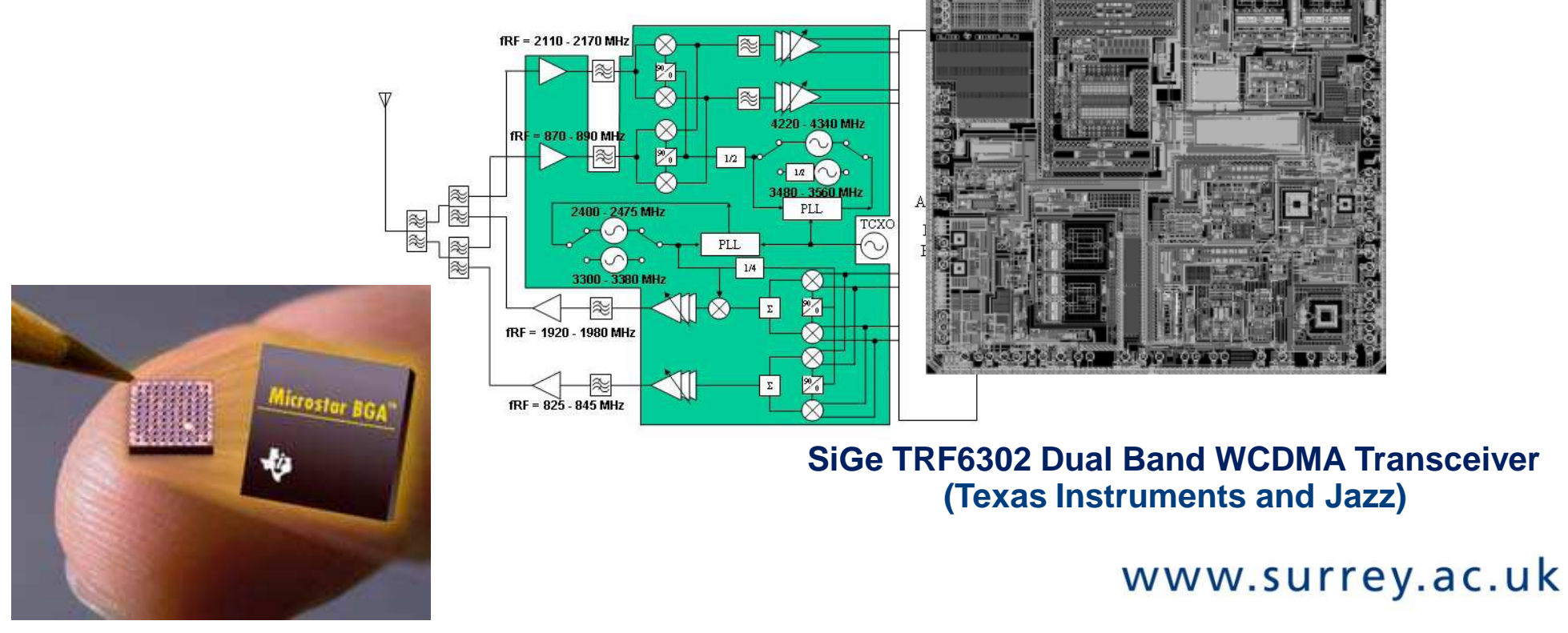




\section{RF Silicon on Insulator (SOI)}

- RF antenna switches on SOI: keys for SOI are isolation and power handling. Isolation of $32 \mathrm{~dB}$ achieved and insertion loss better than $1 \mathrm{~dB}$ up to at least $26 \mathrm{dBm}$ (STM's SP6T).

- RF amplifier examples:

- 1.8 GHz Handset PA+RF Switch, $11 \mathrm{~dB}$ gain, 50\% PAE, $V_{\text {DD }}$ 3.5V (Costa et al, IEEE-MTT-S 2007)

- $5 \mathrm{GHz}$ WLAN LNA, $14 \mathrm{~dB}$ gain, $1.4 \mathrm{~dB}$ NF, $\mathrm{V}_{\mathrm{DD}} 1.2 \mathrm{~V}$, (STMicroelectronics $130 \mathrm{~nm}$ )

- 80 GHz LNA, 7.2 dB gain, 5.7 dB NF (STM 65 nm 2007)

- $\underline{\mathrm{VCO}}$ : $5 \mathrm{GHz},-130 \mathrm{dBc} 1 \mathrm{MHz}$ from carrier

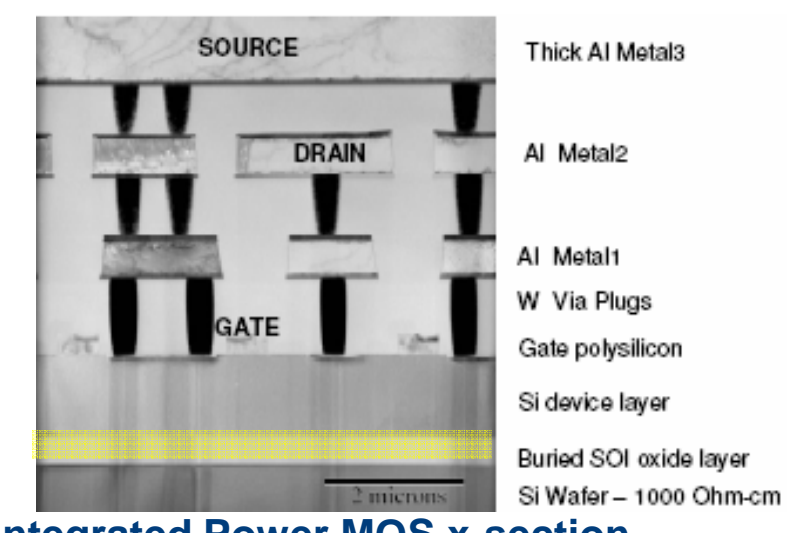

Integrated Power MOS x-section showing Soitec TF-SOI substrate

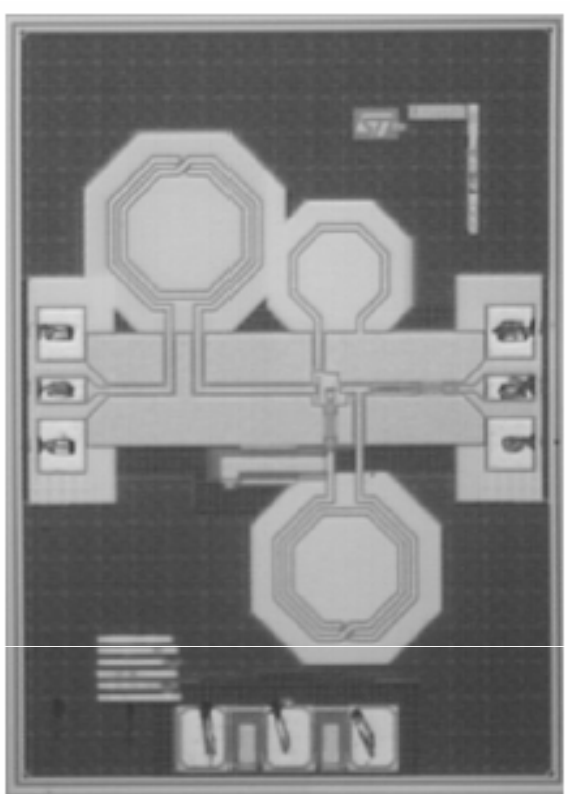

5 GHz LNA: Gianesello, ISIC 2007

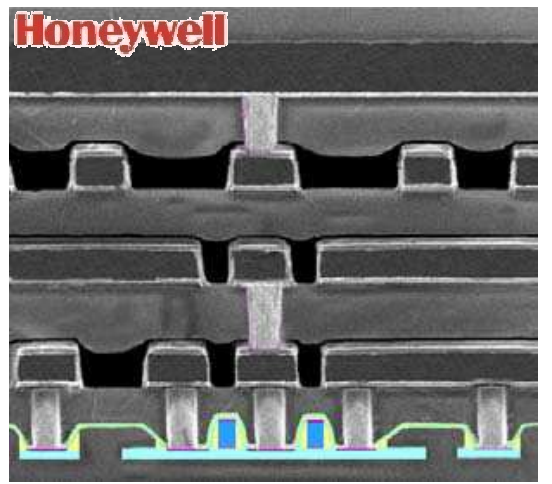

Five layer metal SOI CMOS Integrated Power Amplifier- T/R Switch (RFMD)

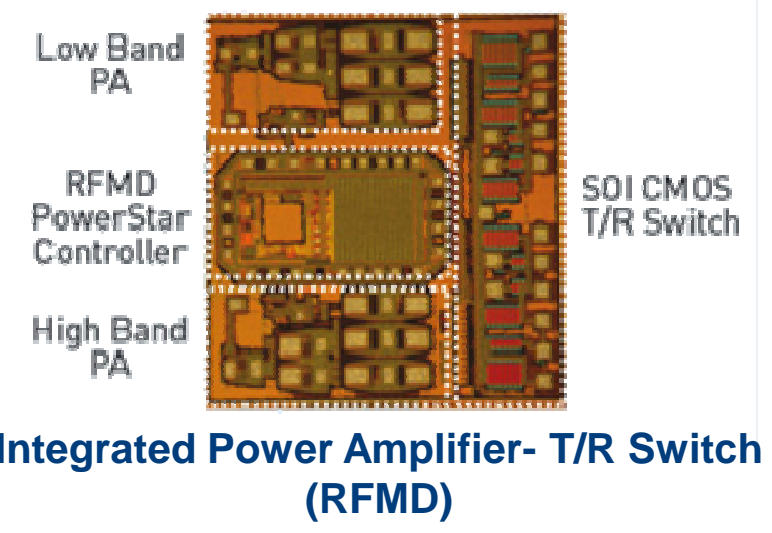

www.surrey.ac.uk 


\section{Compound Semiconductor Technologies}

Despite the scale of Si industry, compound semiconductors still dominate some markets:

- Handset \& WLAN Front End Modules

- Higher frequency applications above $8 \mathrm{GHz}$

- Defence

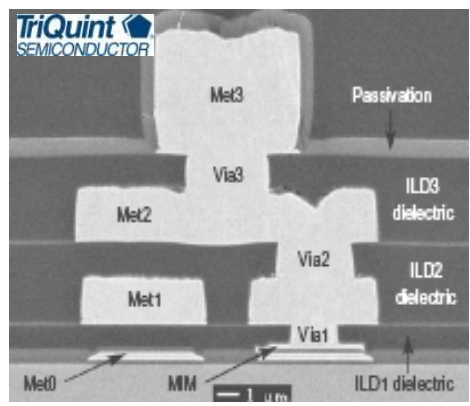

GaAs 150mm wafer diameter, stepper based technology:

- Very cost effective for production quantities into millions.

- GaAs is capable of providing both high volume and high performance technologies:

- MESFET D and E/D, HFET, BiFET, pHEMT D and E/D, HBT, BiHEMT, MHEMT.

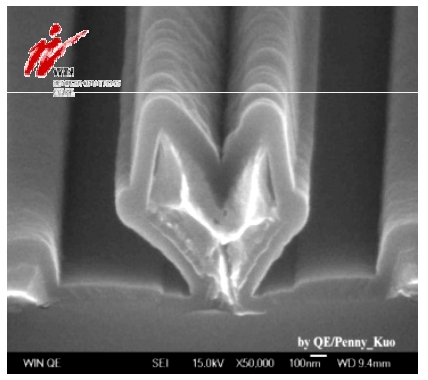

$0.25 \mu \mathrm{m}$ T-gate (WIN)

- Integration of GaAs HBT and E/D mode pHEMT = BiFET (WIN, Triquint, Skyworks, Anadigics)

- Allows single chip PA, switch, LNA, control.

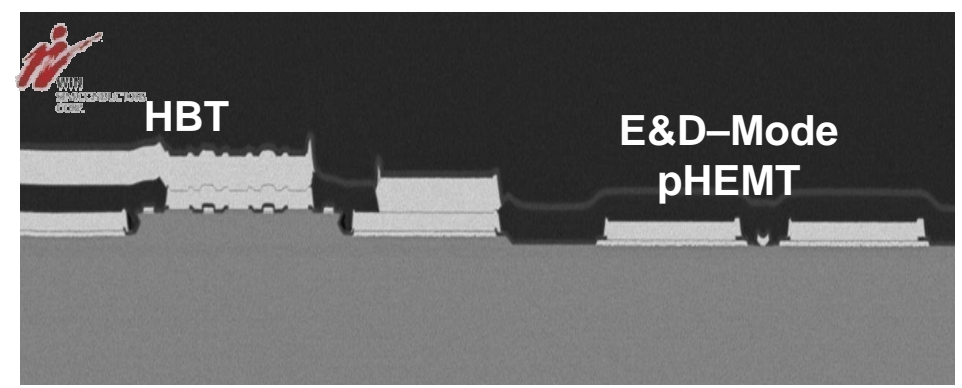




\section{GaAs MMIC Market Growth}

GaAs MMIC Market by Application 2006-2011

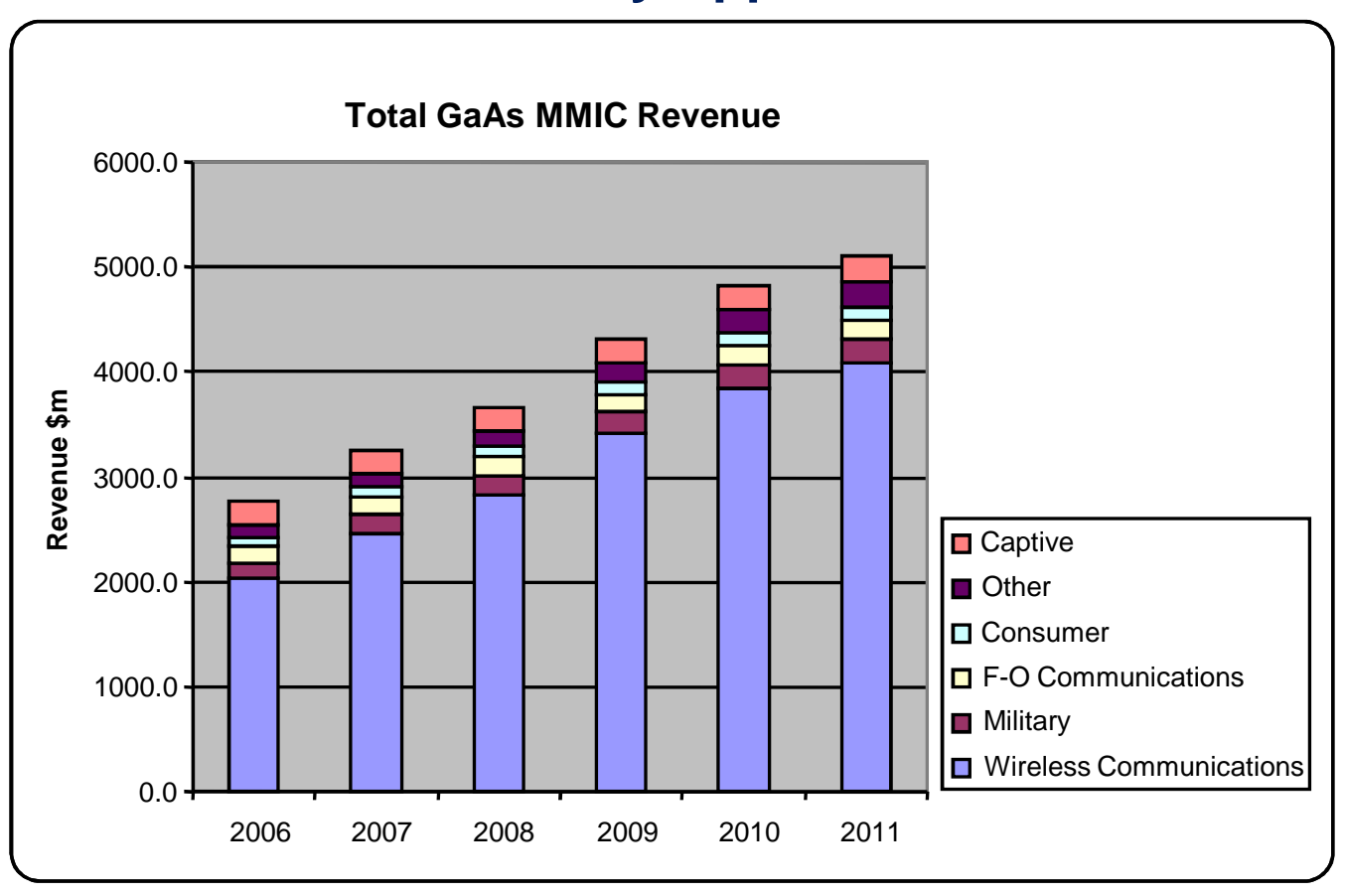

- Cellular 2.5/3G

- WLAN

- 4G (WIMAX, LTE)

- Base stations

- Pt to Pt Radio

- Satellite (VSAT)

- Military - phased array radar

- Automotive

- Other

Source: Strategy Analytics Feb 2008

- $85 \%$ of the GaAs market is in MMICs

- Growth driven by wireless comm's and notably cellular handsets TAM expected to be \$5 Bn by 2011

- 2.5/3G Cellular comm's dominant > \$2.5 Bn.

- Wireless LAN > \$ 1Bn in 2011 


\section{GaAs Foundry Business}

- Success in the GaAs foundry business depends on:

- Having the right technology - a range of technologies is needed today.

- Strong customer support \& ability to identify new customers/markets

- Establishing trusting relationships and excellent product support

- Financial viability for capacity expansion as demand grows and varies.

- Sufficient volume to ensure lower production costs and material costs

- High quality, high reliability and high yield.

- Consolidation has occurred even though market continues to grow:

- Filtronic fab' acquired by RFMD, Suntek exited, GCTC acquired by WIN

- Leaving only four major GaAs foundries in the market today:

- TriQuint Semiconductor, Win Semiconductor, AWSC, GCS

- Successful foundries offer customers a wide range of process technologies and the ability to manufacture wafers in high volume

- High volume means capacity for 10,000 to 100,000 wafer starts per year

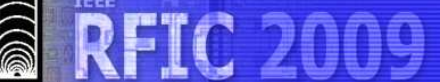




\section{GaAs for Cellular and WLAN}

GaAs pHEMT technology is widely used for high performance cellular and WLAN RF switches - Compact, Low Loss, High Isolation RF Switch for quad band applications

GaAs-based HBT and MESFET technology is used extensively for RF PA's, achieving high efficiencies, good linearity and compact solutions.

Relatively easy designs and tolerance of wide range of VSWR's from antenna.

Flip-chip technology widely used.

Normally integrated using module technology.
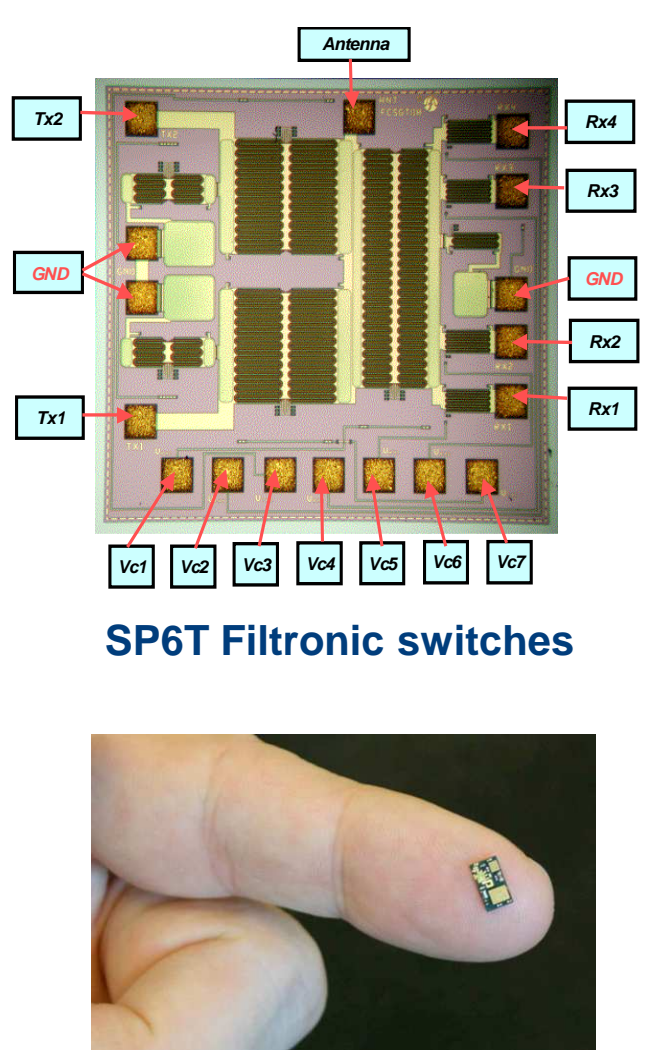

3G PA Duplexer Module (Triquint)
RFMD

RF3146

RFMD PowerStar HBT PA Module

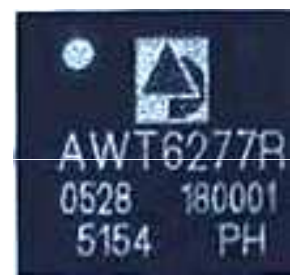

Anadigics CDMA PA HBT+FET on same die

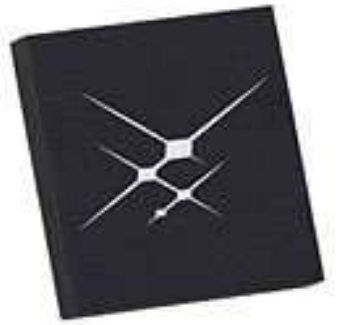

Skyworks Chip Sets 


\section{Microwave and Millimetre-Wave Multi-function GaAs MMICs}

- High performance microwave and millimetre-wave MMICs - cost-effective solutions from 1 to $60 \mathrm{GHz}$.

- Cost reduction and performance improvement in point-point and other demanding RF systems.

- Multi-function MMICs used in Filtronic point-point system reduced part-count 20 -fold, with faster assembly, less tuning and higher reliability.

Courtesy Filtronic plc

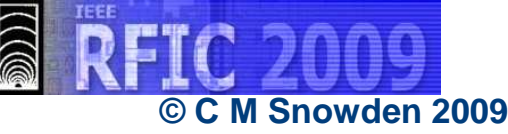

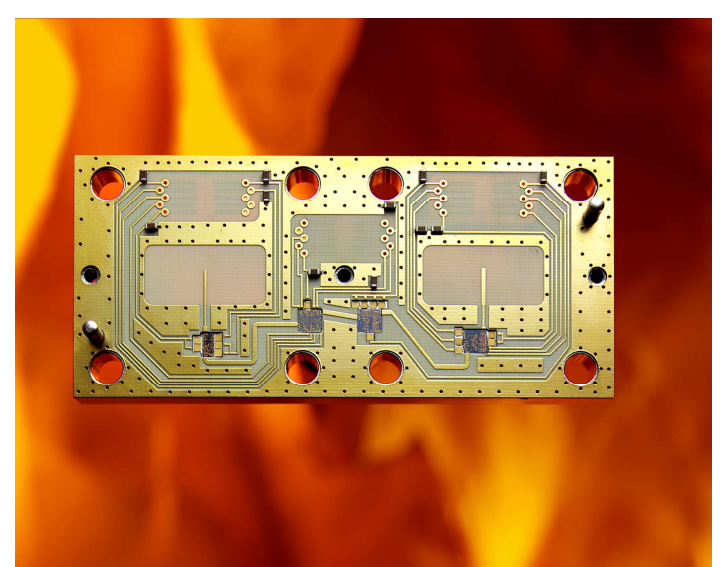

Complete microwave point-point Transceiver

-15 parts (Filtronic).

\section{UNINERSITY OF SURREY}

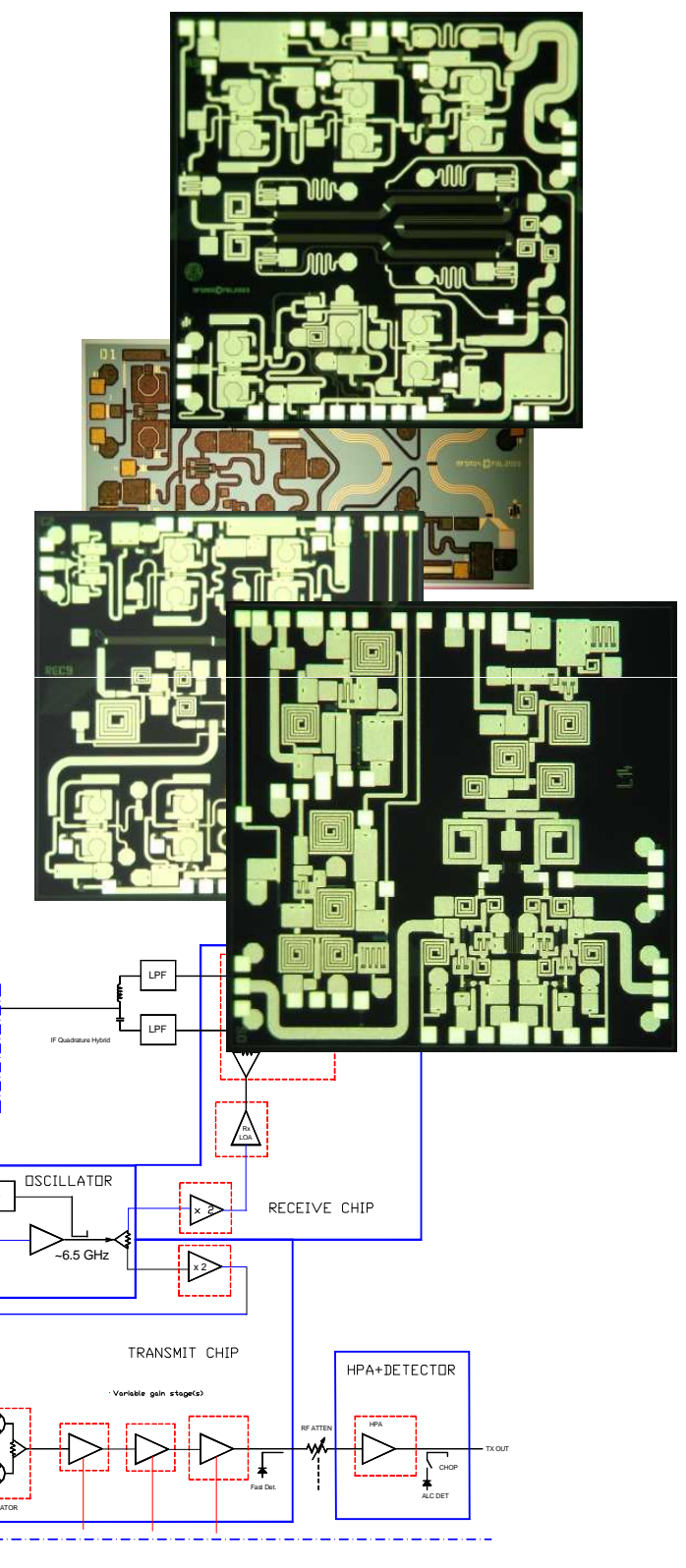




\section{Increasing Scale - 150mm Wafer Compound Semiconductor Fabs}
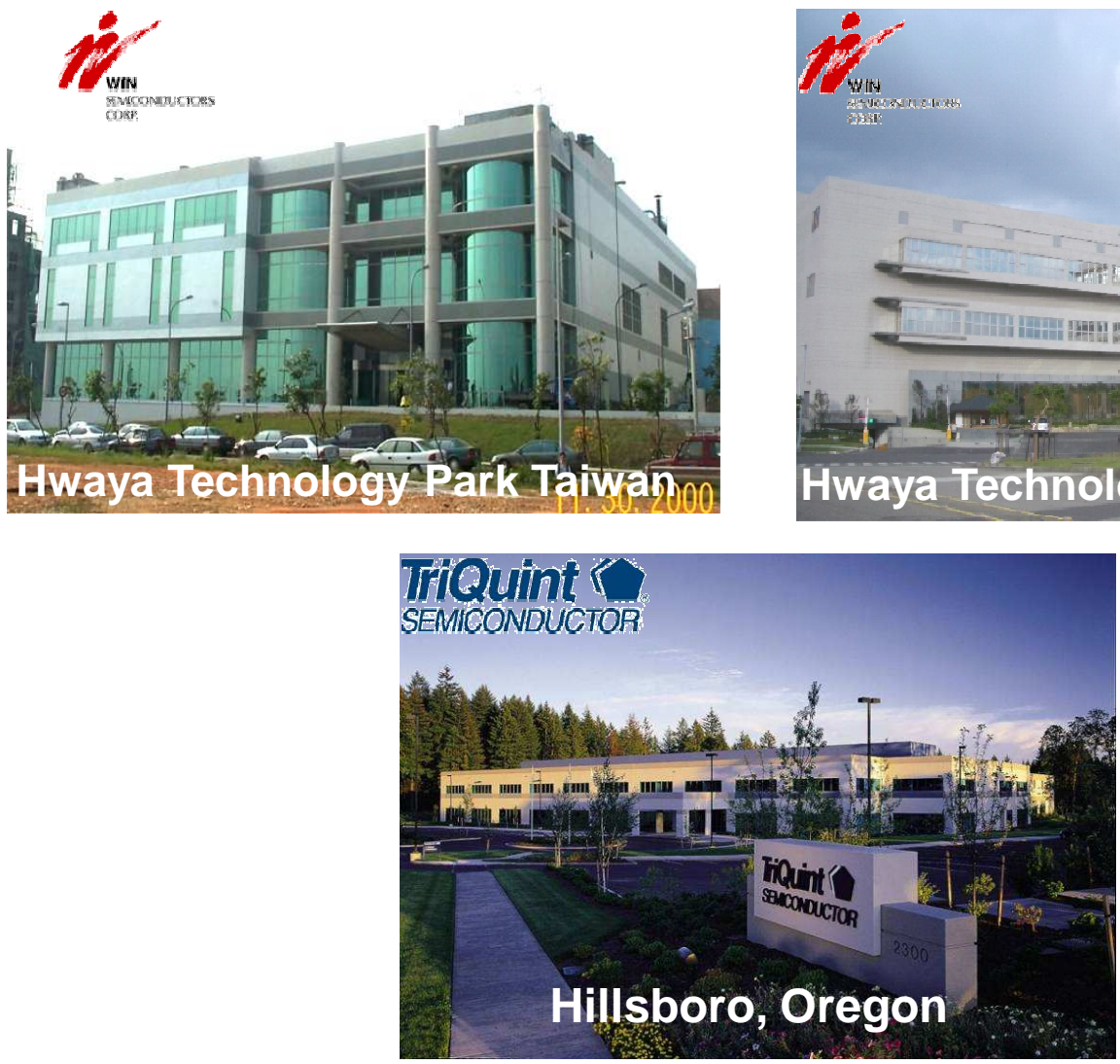
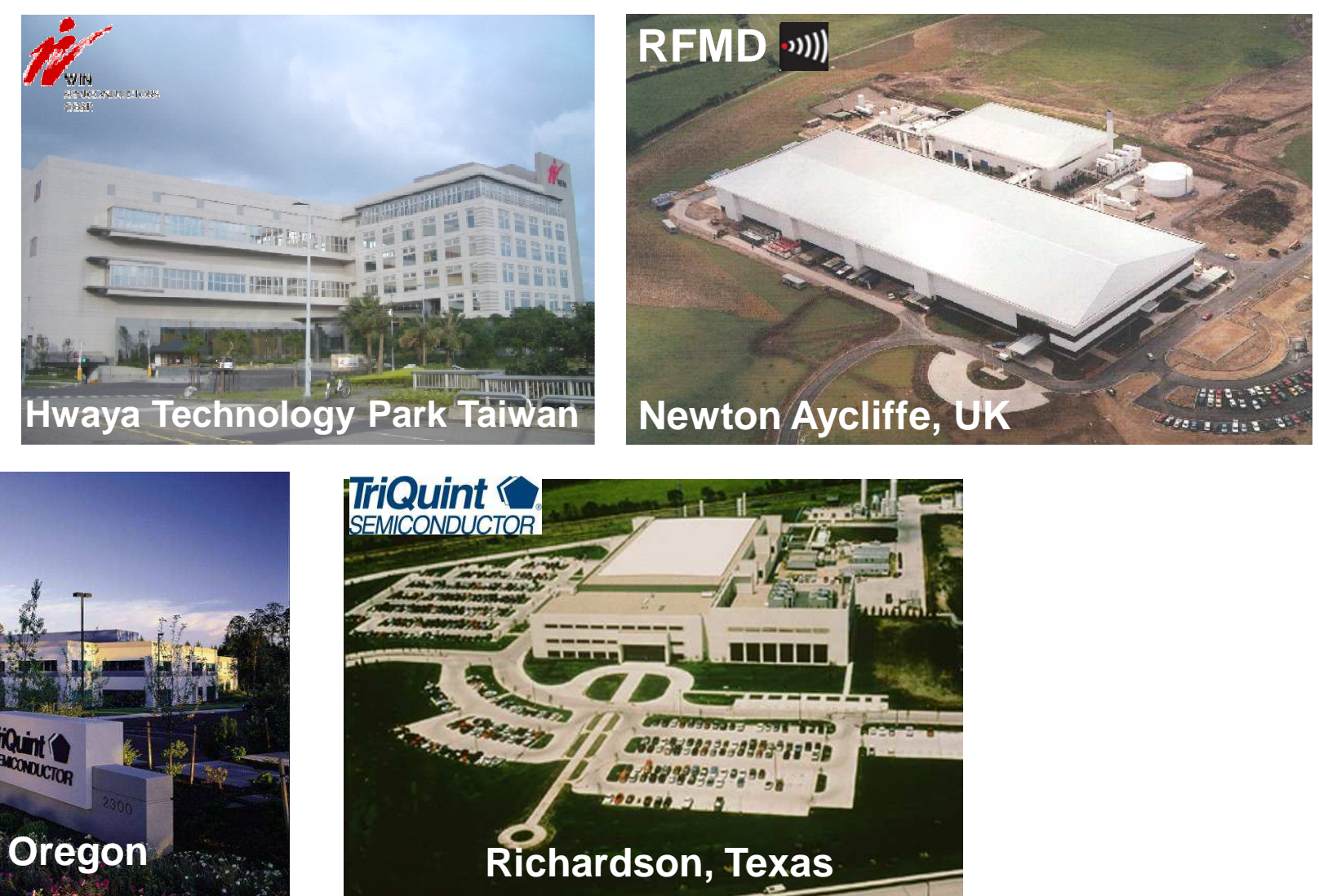

- Modern, $150 \mathrm{~mm}$ GaAs facilities, with high volume, high yield and low finished wafer costs.

- Success of foundry model now in GaAs, as in Si and SiGe. 


\section{Integration Trends - On-Chip PAs USURREY}

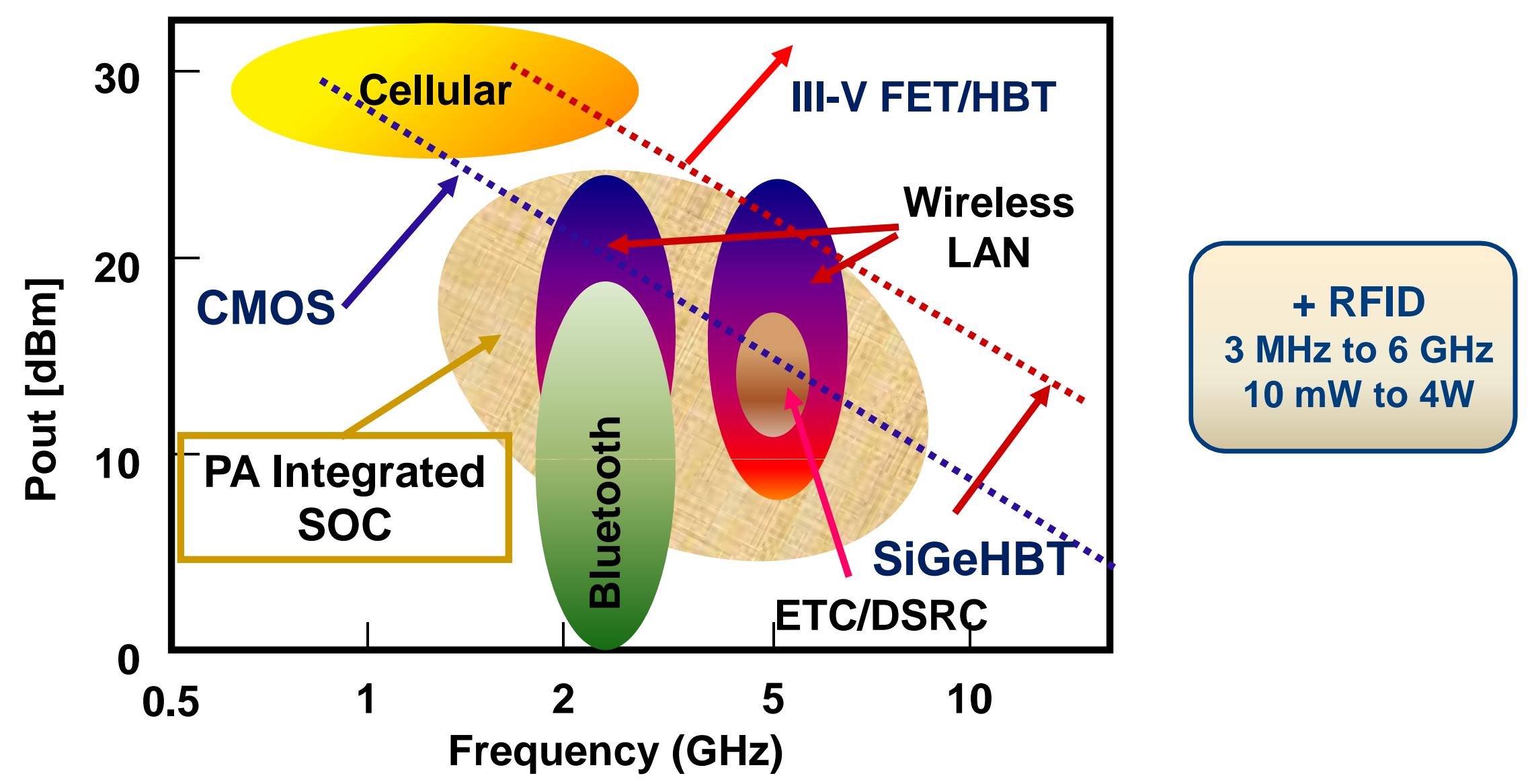

- PA is the most expensive RF element.

- TX power range below $1 \mathrm{~W}$ is the target of PA integrated SOC.

- PA IC/module: \$1. On-chip PA: $1.5 \mathrm{~mm} \times 2 \mathrm{~mm}=\sim \$ 0.15$

- Below 1W output power can be delivered using an on-chip PA 2-6GHz 


\section{Increasing function/area - On-Chip PA - Reducing inference in MMICs}

Unwanted Coupling through surface or near surface of IC can occur.

\section{Improving on-chip isolation:}

- Reduction by Circuitry

- Use differential configuration/elements.

- Reduction of Leakage through Surface

- Use multi-well / deep trench isolation.

- Use wider on-chip shielding GND metal.

- Reduction of Leakage though Bulk

- Use GND VIA, but expensive

- Use thinner Si-substrate.

Thinning from 300 to 125 microns (5 mil) gives a $12 \mathrm{~dB}$ improvement in isolation..

- Design of differential PA without current source improves $\mathrm{P}_{\text {sat }}$. Consideration of imbalanced operation is important for reactive inter-stage matching PA.

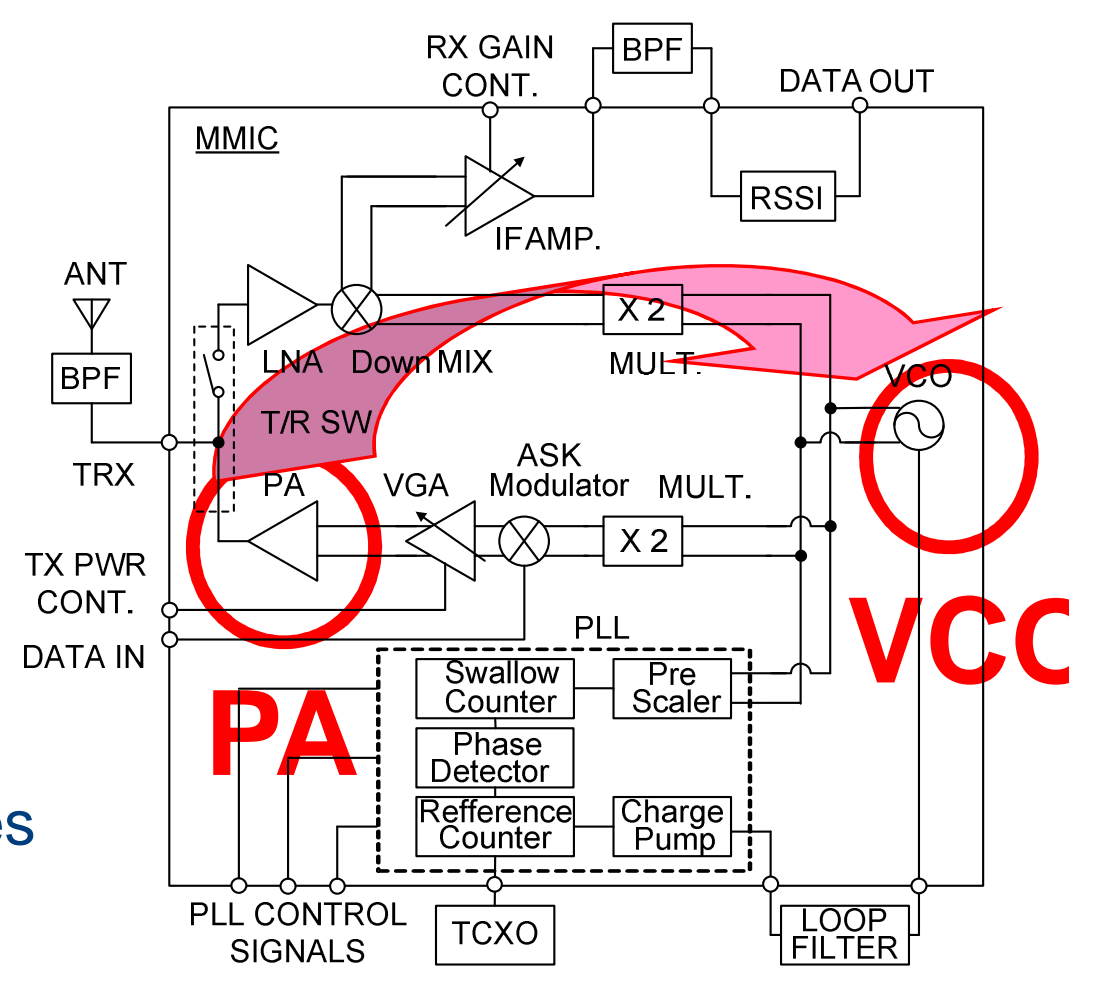




\section{Integration - SiGe 5.8 GHz TRX-MMIC}

Tx output power

Tx ACPR

Rx NF (DSB)

$R \mathbf{x}$ conversion gain

Rx phase noise

Current consumption $366 \mathrm{~mA}$

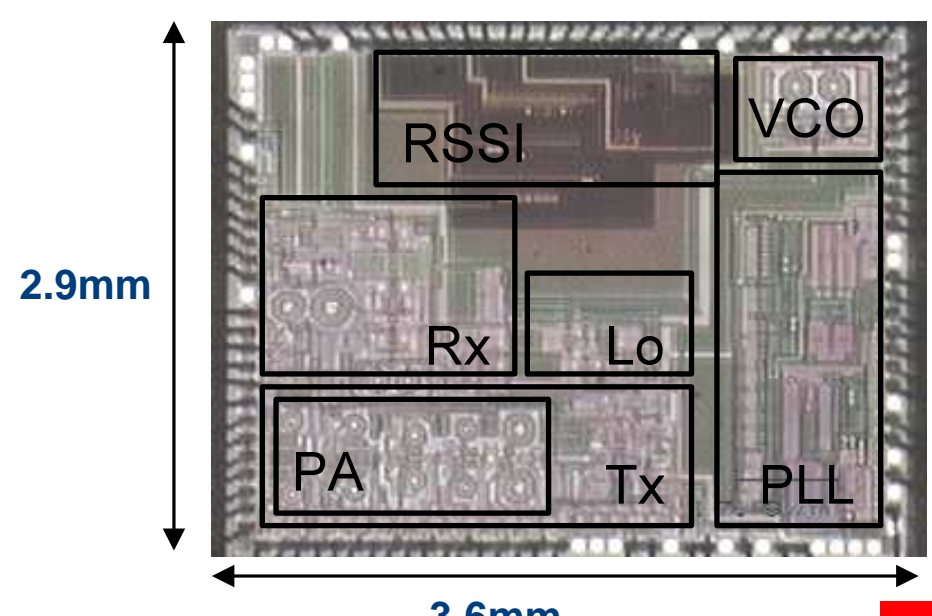

$15.5 \mathrm{dBm}$

$-33.5 \mathrm{dBc}$

$11.2 \mathrm{~dB}$

22.0dB

$-106.7 \mathrm{dBc} / \mathrm{Hz}$ at $1 \mathrm{MHz}$ offset

$3.6 \mathrm{~mm}$

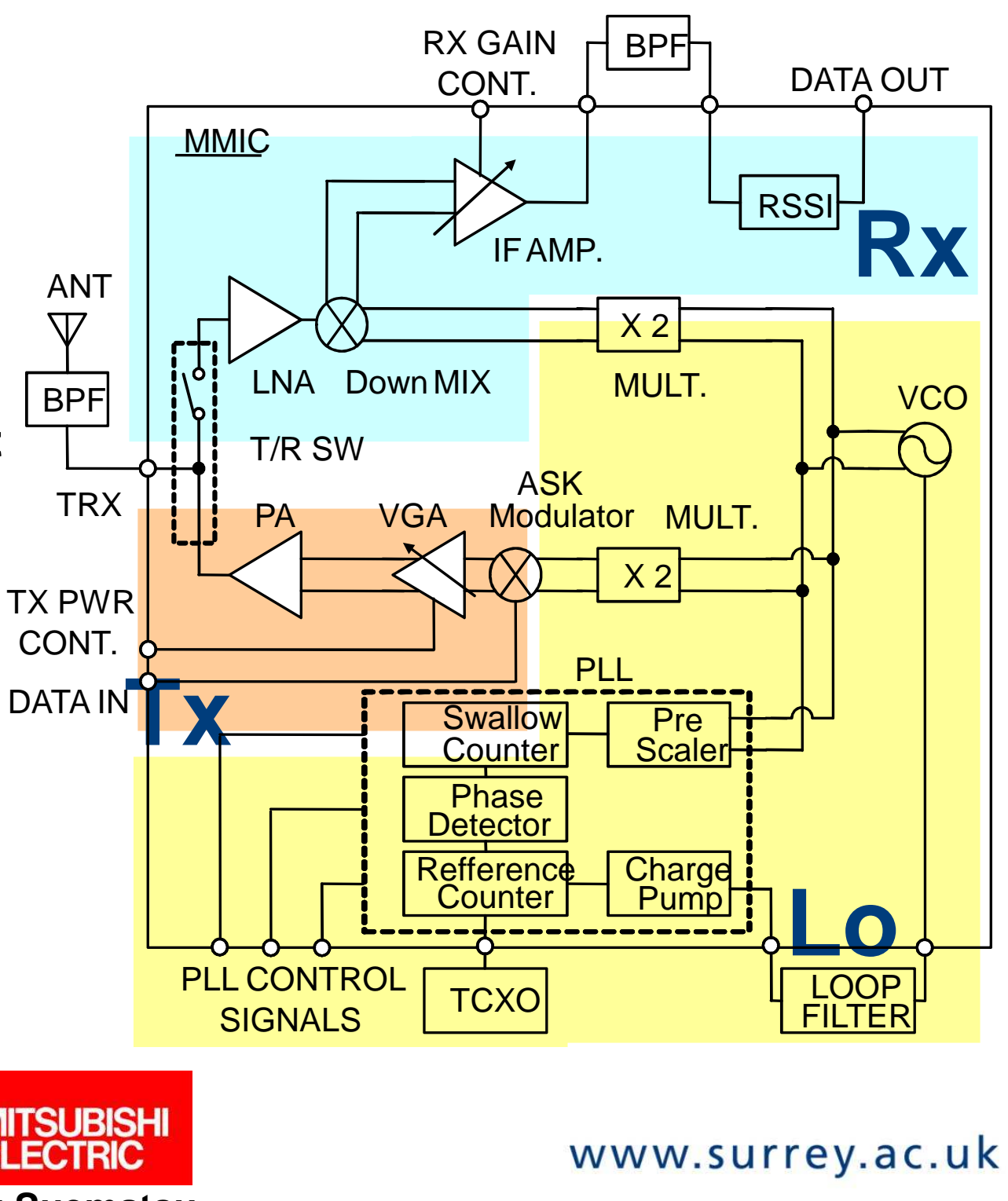

Noriharu Suematsu 


\section{Low Cost RF GaAs Integration}

Die Level Integration

- E/D pHEMT

- BiHEMT

- GaAs passives

- Copper Flip Chip
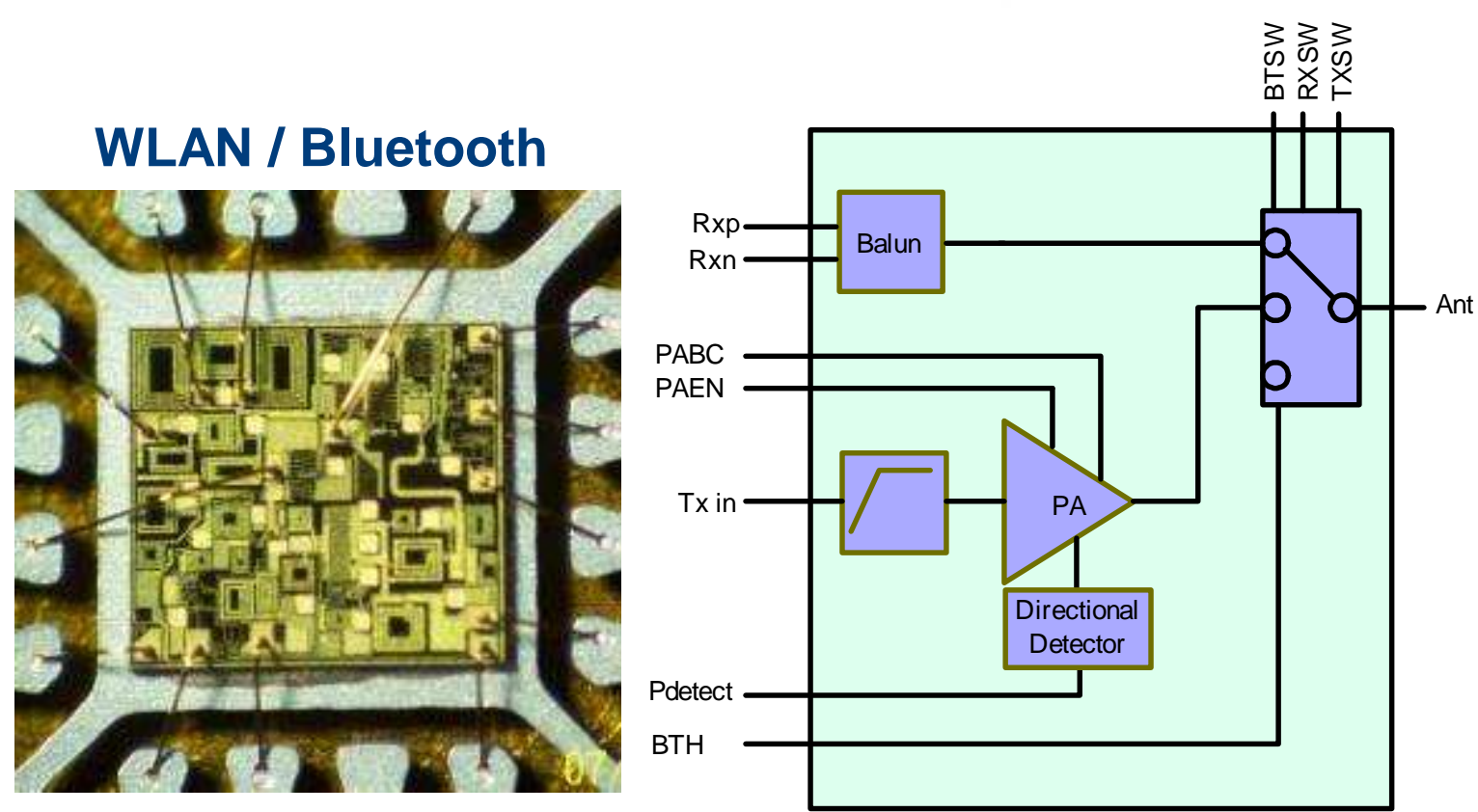

Module Integration

- Power Amplifiers

- Switches

- BAW/SAW Filters

- Embedded passives

GPS: SAW-LNA-SAW
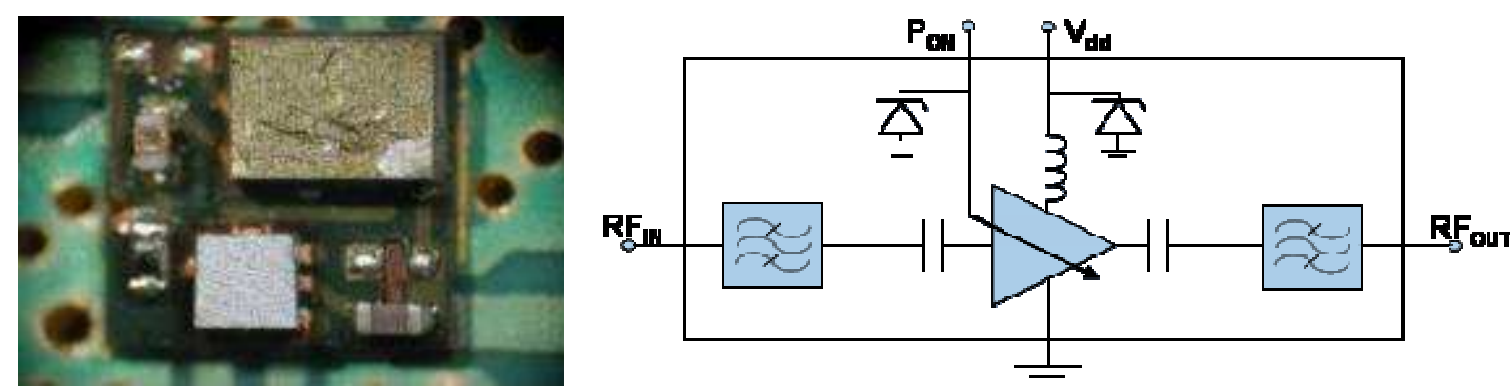

www.surrey.ac.uk 


\section{Integration - Flip Chip Modules}

- Flip-chip technology based on Cu bumps allows cost-effective module assembly.

- Triquint produced first Flip-Chip based GSM PA Module in volume in Feb 2005.

- Very compact GSM PAM $\left(5 \times 5 \times 1.1 \mathrm{~mm}^{3}\right)$

- Excellent RF Performance

- Low cost, high-volume production

- Flip chip technology widely used now.
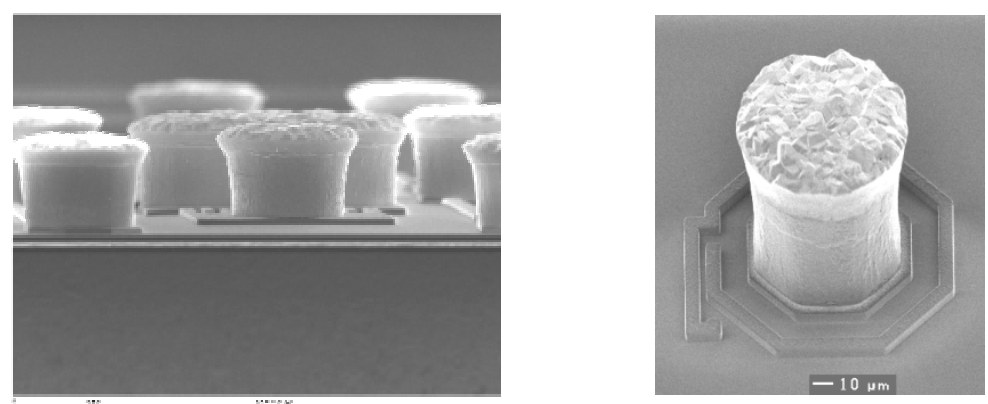

Copper Bump Images

Courtesy of

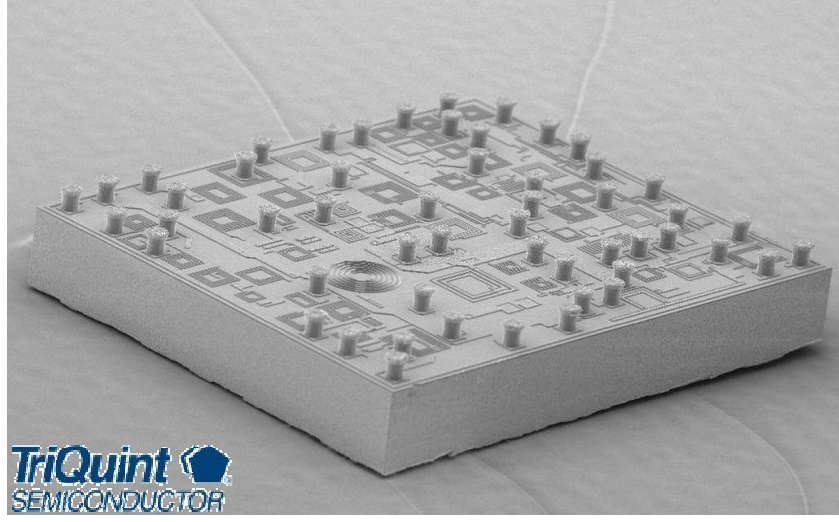

GaAs

HBT

TriQuint 7M4006 GSM PAM

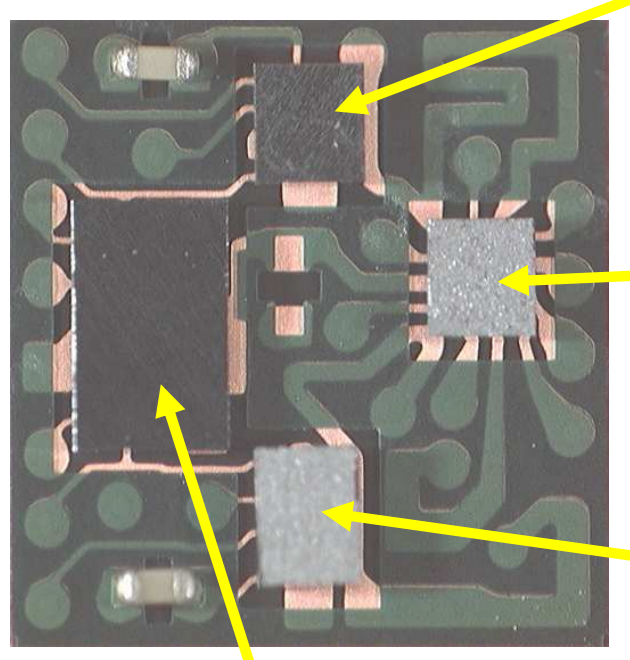

HB PA Die

GaAs

Passive

Output

Match

GaAs

HBT

LB PA Die

Controller 


\section{Multi-Chip Assemblies and Packaging for High Volume Cost-sensitive RF applications

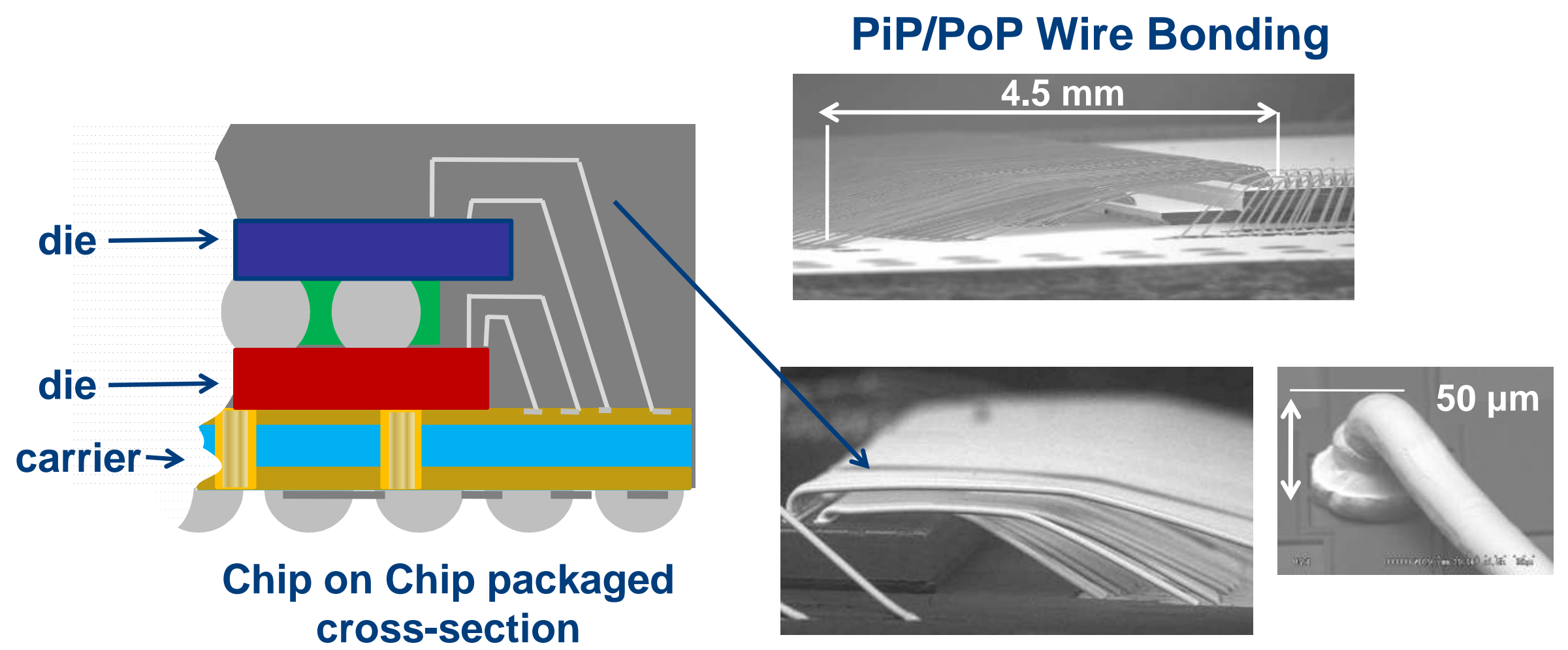

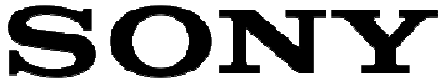

Advanced LSI packaging
PiP: Package in Package

PoP: Package on Package 


\section{Multi-Chip Assemblies and Packaging for High Volume Cost-sensitive RF applications

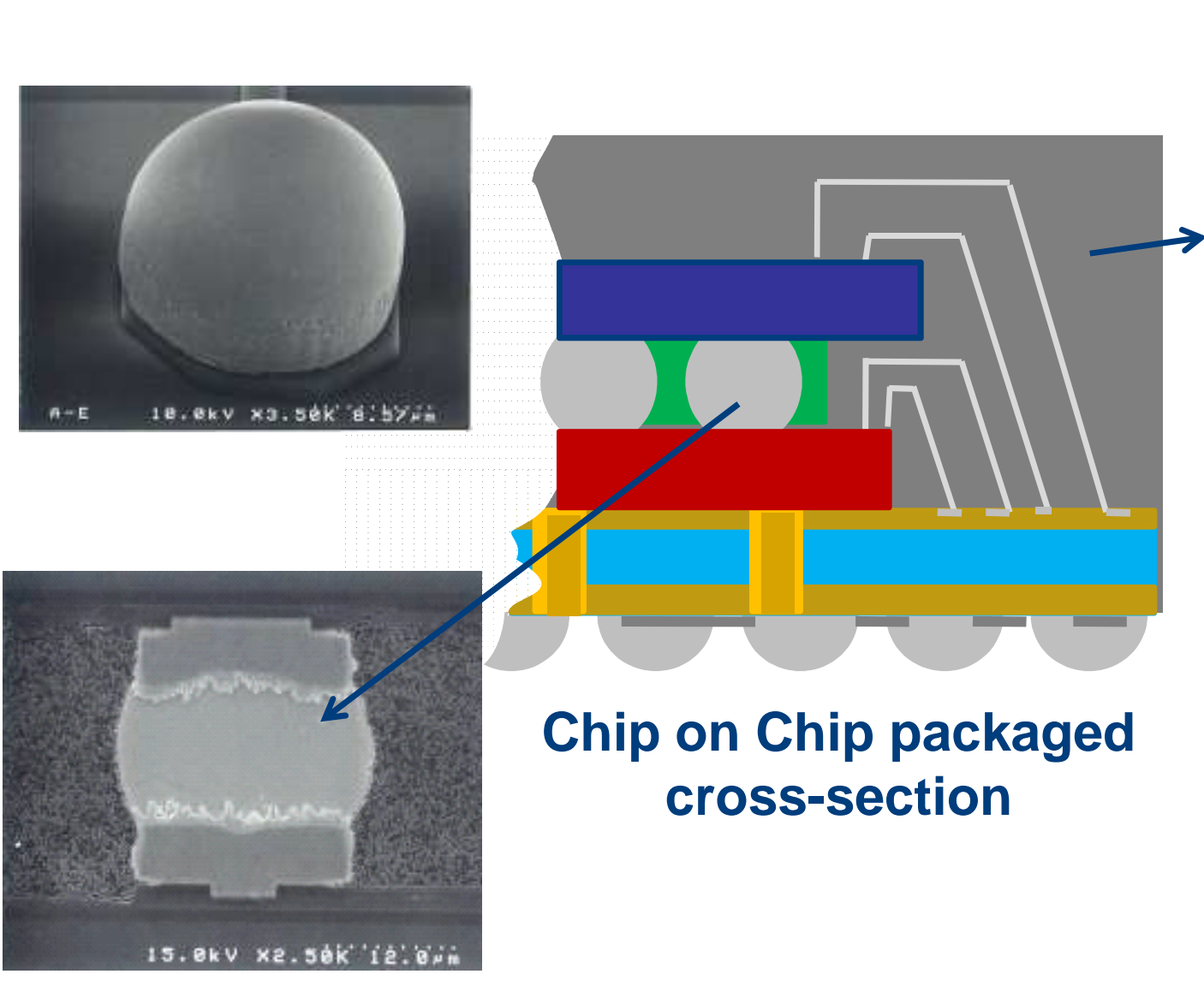

Chip on Chip

\section{Wire Bond}

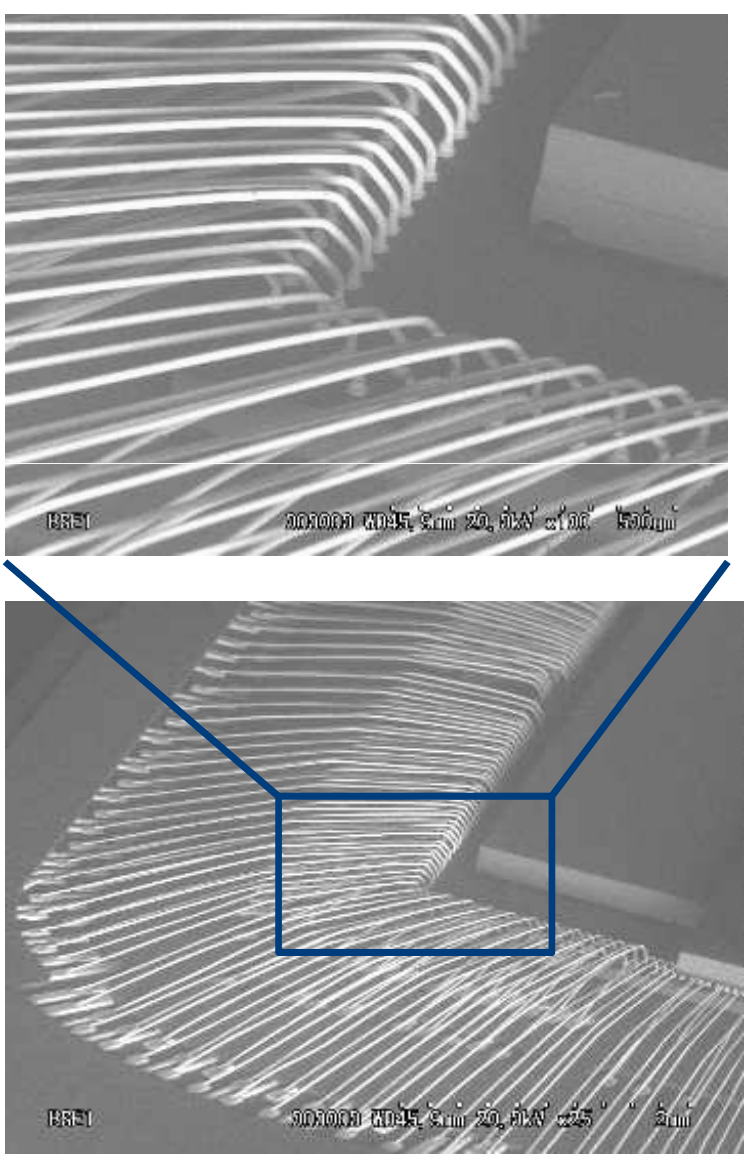

\section{SONY}




\section{RF Power Transistor Market}

- RF Power transistors used in:

- Wireless infrastructure, $>50 \%$ of the market

- Broadcast

- ISM

- Military

- Commercial avionics and non-cellular communications

- Total accessible market for Power Transistors below $3 \mathrm{GHz}$ currently $\$ 750 \mathrm{~m}$ and will exceed $\$ 800 \mathrm{~m}$ by 2011

- Volume for W.I. market growing but price pressure causing slight decline in overall revenues - other markets show good growth in the next 5 years.

- Key technologies: LDMOS, GaAs FET and emerging GaN HEMT. 


\section{RF Power Semiconductors - LDMOS}

- LDMOS

- Dominant in cellular infrastructure space

- LDMOS is the leading RF PA device technology for the cellular infrastructure market - beats all others on cost.

- Proven reliability

- 50V technologies now being introduced ( $\eta>73 \%$ with $23 \mathrm{~dB}$ gain)

- Maximum frequency of operation currently at 3.8 GHz - likely to rise to $5 \mathrm{GHz}$ (currently $\mathrm{f}_{\mathrm{T}}>11 \mathrm{GHz}$ )

- Challenged by III-V technology in applications above $4 \mathrm{GHz}$.

- GaAs and GaN have higher $\mathrm{f}_{\mathrm{T}}$, current/mm and power densities.

- LDMOS has demonstrated excellent Doherty PA performance, and is being developed for other architectures (Class F, Drain Mod, etc)

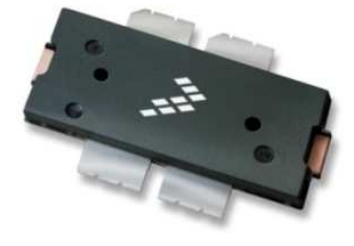




\section{Cost drivers in RF HPAs}

- Power Amplifier devices are major contributors to system BOM cost

- Device level cost drivers include packaging \& semiconductor

- Integration and low cost over-molded plastic packaging are innovative ways to effectively respond to price pressures

1.8-1.9 GHz GSM Edge Chipset

OVM Plastic GPA +

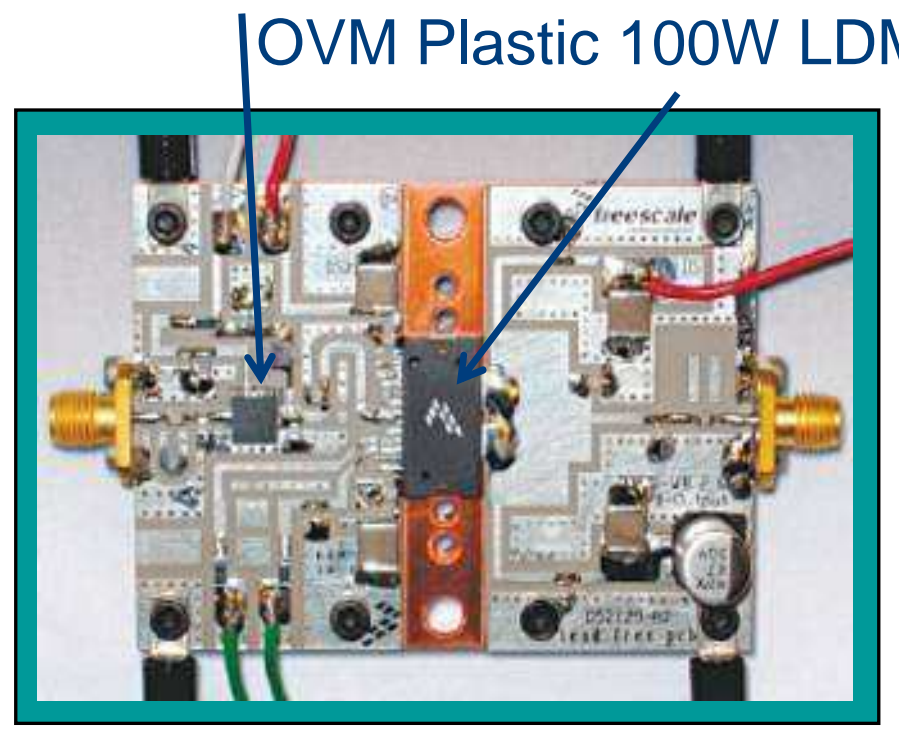

- 47dB Gain

- 100W GMSK / 40W Edge

-40\% PAE @ 48.5dBm

- Fixture size 70 x $50 \mathrm{~mm}^{2}$

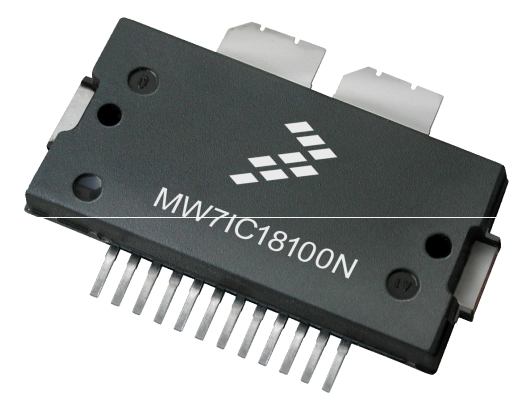




\section{High efficiency HPAs based on LDMOS power ICs}

- A Linear 250 Watt Doherty Power Amplifier

- Based on Two-Stage Power ICs for 1.8 GHz Single and Multi-Carrier GSM Applications using $2 \times$ MW7IC18100

- A 900 MHz, 200 W Silicon LDMOS Power

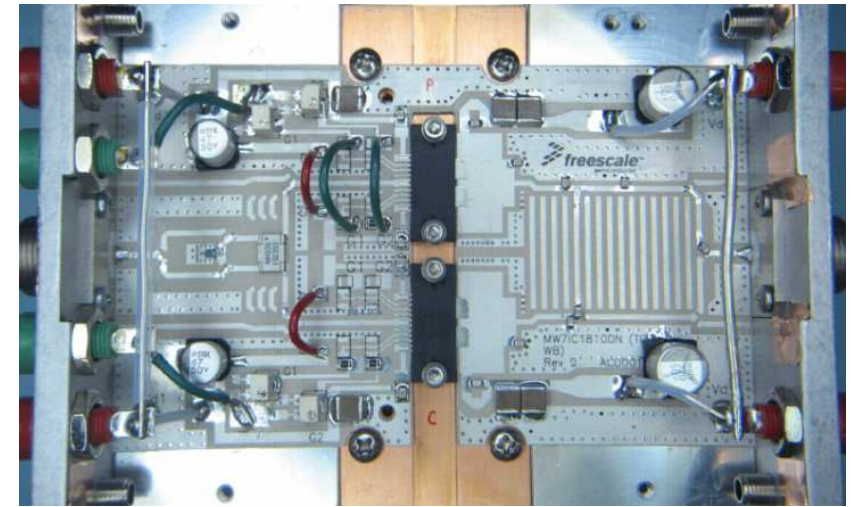
Amplifier using Integrated Passive Devices in a New Over-Molded Plastic Package

- highest reported RF power in a plastic package

- Input match with integrated passive IC, output match with MOSCAP \& bond wires "freescale

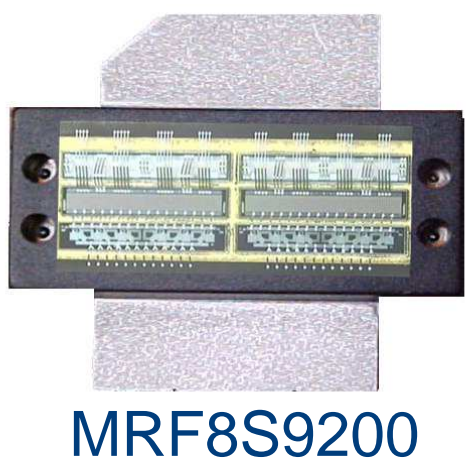

Papers on these amplifiers will be presented at IMS on Thursday, Session TH3A

www.surrey.ac.uk 


\section{GaAs Power Transistor Technologies}

- Low cost base, mature and established technology.

- pHEMT or MESFET technologies on $150 \mathrm{~mm}$ o

- Very good gain and power up to $60 \mathrm{GHz}$

- Can compete at $\sim \$ 1 /$ Watt up to $5 \mathrm{GHz}$.

- Large devices up to $100 \mathrm{~W}$ per die $\sim 200 \mathrm{~mm}$ gate periphery

- $3 \mathrm{~W} / \mathrm{mm}, 65 \%$ PAE at $3.5 \mathrm{GHz}$ (Triquint)

- $800 \mathrm{~mW} / \mathrm{mm}, 53 \%$ PAE at $29 \mathrm{GHz}$ (WIN)

- Substrates can be thinned to $50 \mu \mathrm{m}$ thickness

- low inductance via and low thermal resistance

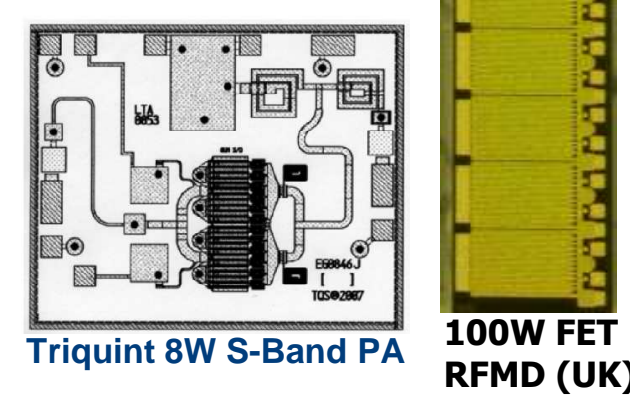

- High breakdown Voltage of typ. 35V (up to 80V).

- Outstanding reliability $->10^{10}$ hours at $125^{\circ} \mathrm{C}$

- Outstanding production yield possible

- eg: 96\% KGD for an X-Band 5W MMIC

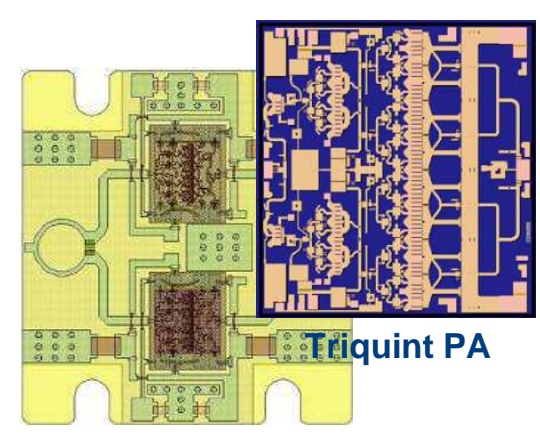

X-Band 19W CW $40 \%$ efficiency www.surrey.ac.uk 


\section{Gallium Nitride Power Transistors}

- $\mathrm{GaN}$ - on SiC or on Si substrates.

- 10x higher breakdown electric field than GaAs or Si.

- High saturated velocity than GaAs or Si

- Advantages

- Higher voltage operation (50V or higher)

- High current capability $(1 \mathrm{~A} / \mathrm{mm})$ and high power densities.

- Higher frequency operation up to $80 \mathrm{GHz}$

- High temperature compatibility (excellent thermally)

- Higher impedance levels for a given power - attractive.

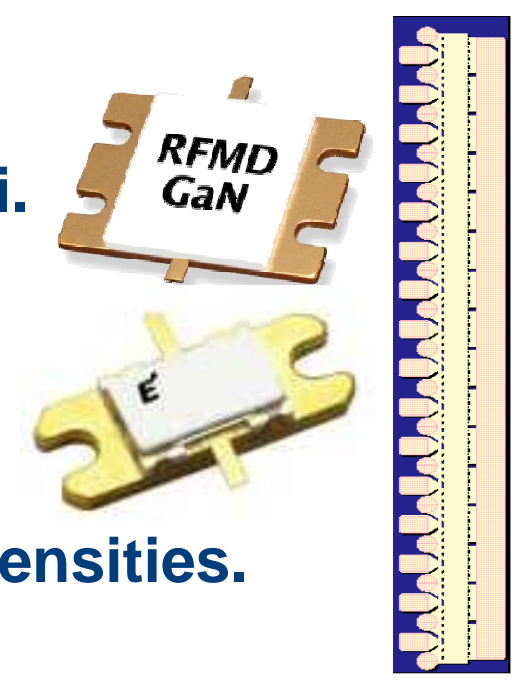

Triquint 100 Watt GaN on SiC (20mm)

- Challenges

- Cost is likely to remain a challenge compared to GaAs or LDMOS.

- Material quality/defect density concerns (yield, performance anomalies)

- Reliability data improving. Infrastructure applications are very demanding.

- Applications from RF to millimeter-wave including LNAs and PAs.

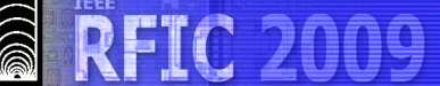




\section{GaN High Power Transistors}

- RFMD demonstrated a 400W, 48\% PAE, $10 \mathrm{~dB}$ gain HPA at $3.5 \mathrm{GHz}$, using $2 \times 22.2 \mathrm{~mm}$ devices operated at $\mathrm{V}_{\mathrm{DD}}=65 \mathrm{~V}$ (10\% duty cycle)

- Eudyna has achieved breakdown voltages of $350 \mathrm{~V}$ from their GaN commercial range with $53 \mathrm{dBm}, 57 \%$ PAE at $2.6 \mathrm{GHz}$ at $\mathrm{V}_{\mathrm{DD}}=50 \mathrm{~V}$

- Triquint have 100 Watt GaN single die on SiC single achieving $46 \%$ PAE with $15 \mathrm{~dB}$ gain, at $3.5 \mathrm{GHz}$ operated at $\mathrm{V}_{\mathrm{DD}}=40 \mathrm{~V}$.

- Nitronex launched a 200W packaged part in January 2009 achieving $63 \%$ efficiency with $18.3 \mathrm{~dB}$ gain at $900 \mathrm{MHz}$, operating from $28 \mathrm{~V}$.

- GaN power FETs are well suited to switching designs such as Class E and pre-distortion designs.

- GaN HEMTs allow LNAs to have very high intercepts - ideal for radar applications.
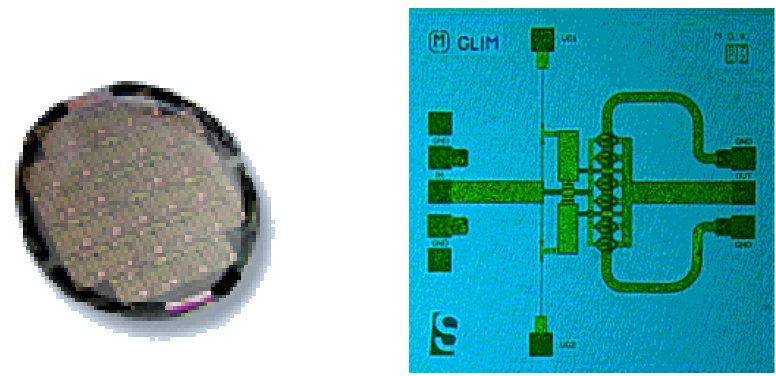

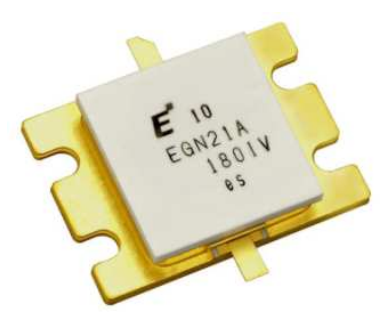

(C) C M Snowden 2009

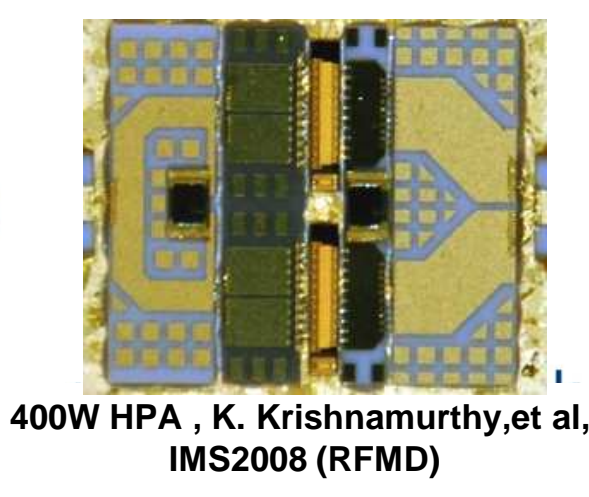




\section{$77 \mathrm{GHz}$ Technology for Automotive Radar}

- The $77 \mathrm{GHz}$ automotive radar market is highly costsensitive

- Compact designs are essential

- High performance, reliable technology is essential

- GaAs pHEMT technology capable of delivering $77 \mathrm{GHz}$ MMIC technology for automotive radar since 1995

- Die size shrinkage $\mathbf{7}$ fold in area in $\mathbf{1 0}$ years.

- Multichip and multi-technology solutions.

- SiGe $77 \mathrm{GHz}$ solutions available (incl. single chip):

- Jazz 180nm SiGe BiCMOS with VCO, tripler, PA, pre-scaler.

- Hajimri's single chip phased-array radar transceiver in IBM8HP SiGe (Caltech)

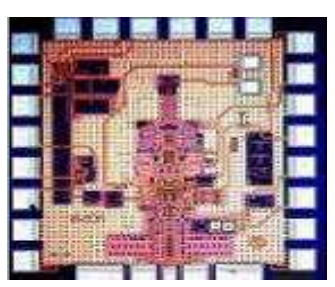

SiGe $77 \mathrm{GHz}$ VCO

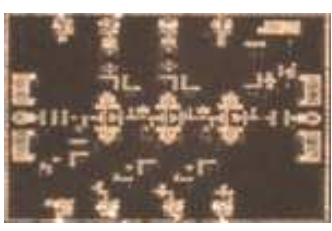

77GHz GaAs Power Amplifier

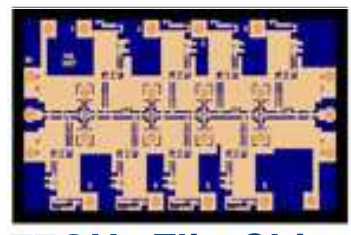

77GHz Flip-Chip Low Noise Amplifier

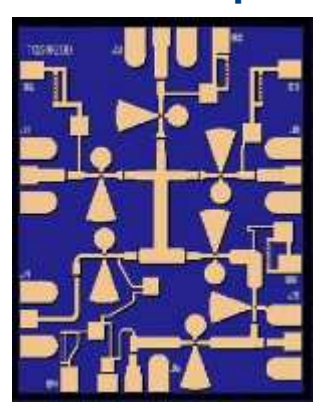

77 GHz GaAs Switch Triquint 


\section{Si and polySiGe MEMS Switches}

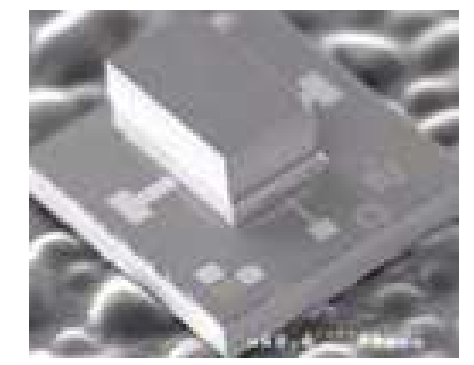

Radant MEMs Switch

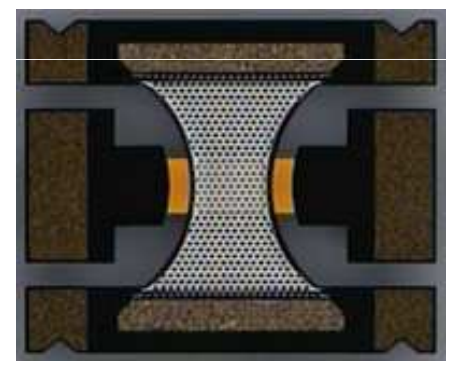

Memtronics RF switch (Capacitive)

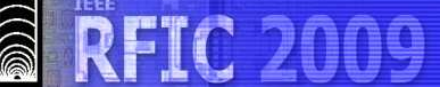

- RF MEMs now available in volume and suitable for chip-on-chip assembly.

- RF MEMs switches have high linearity.

- MEMs market expected to grow to over $\$ 200 \mathrm{~m}$ by 2011 , in test and instrumentation, wireless infrastructure, defence.

- Electrostatic MEMS switches have a been shown to have 100 billion switching cycles (Radant).

- MEMS switches have been incorporated at wafer level.

- Insertion loss $<0.5 \mathrm{~dB}$ up to $38 \mathrm{GHz}(\sim 0.3 \mathrm{~dB}$ at $2 \mathrm{GHz})$.

- Isolation $20 \mathrm{~dB}$ at $10 \mathrm{GHz},>23 \mathrm{~dB}$ at $2 \mathrm{GHz}$

- On-response time $5 \mu \mathrm{s} .40-120 \mathrm{~V}$ actuating voltage.
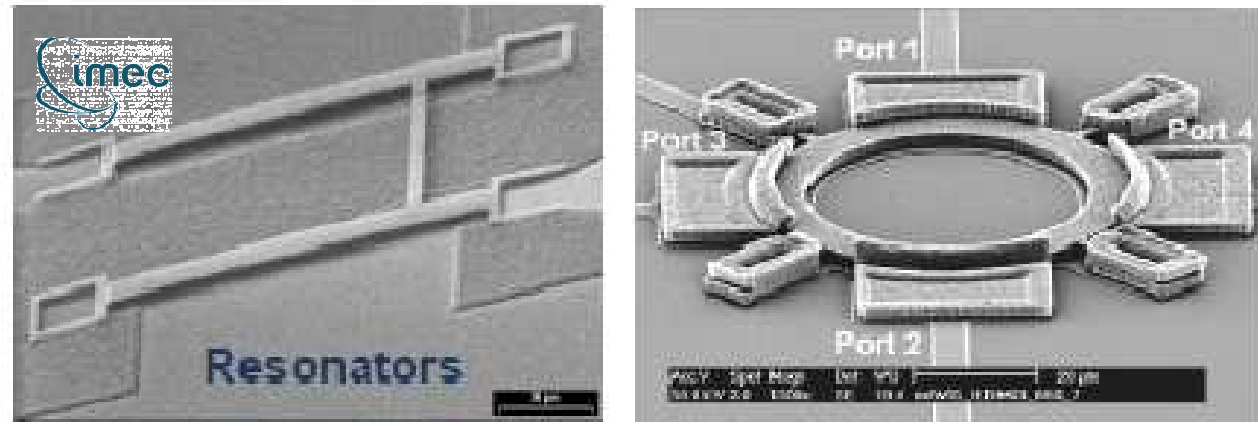

C. Claeys, IMEC 


\section{Future ICT Technology Drivers}

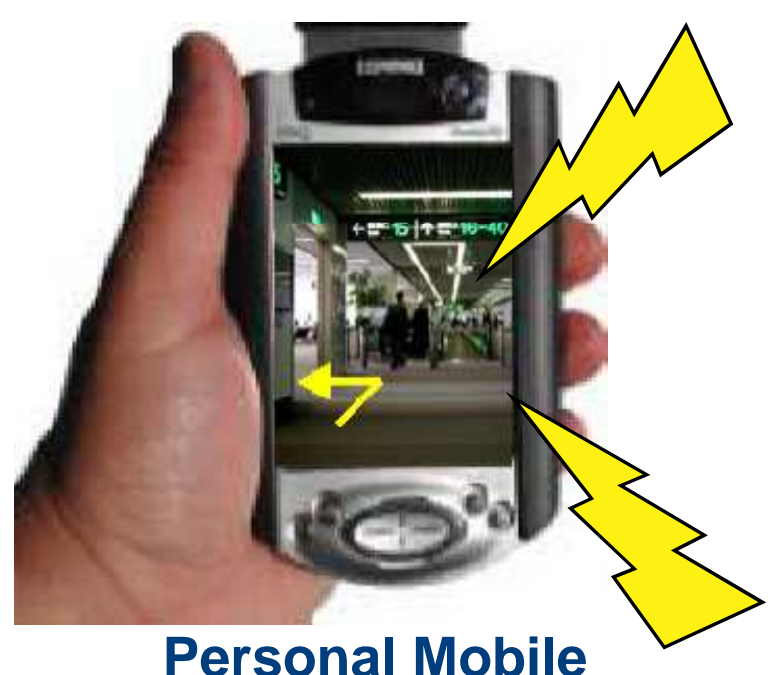

Personal Mobile

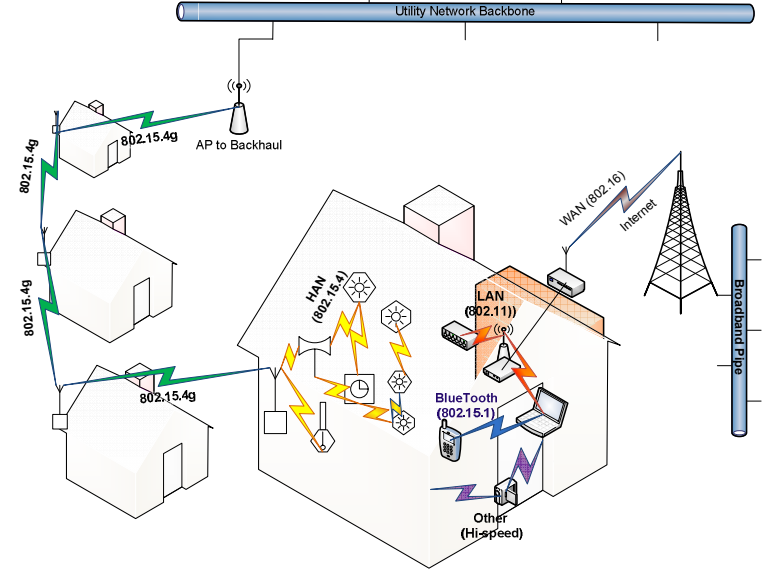

Smart Utility Networks

Wearable health and comfort monitoring
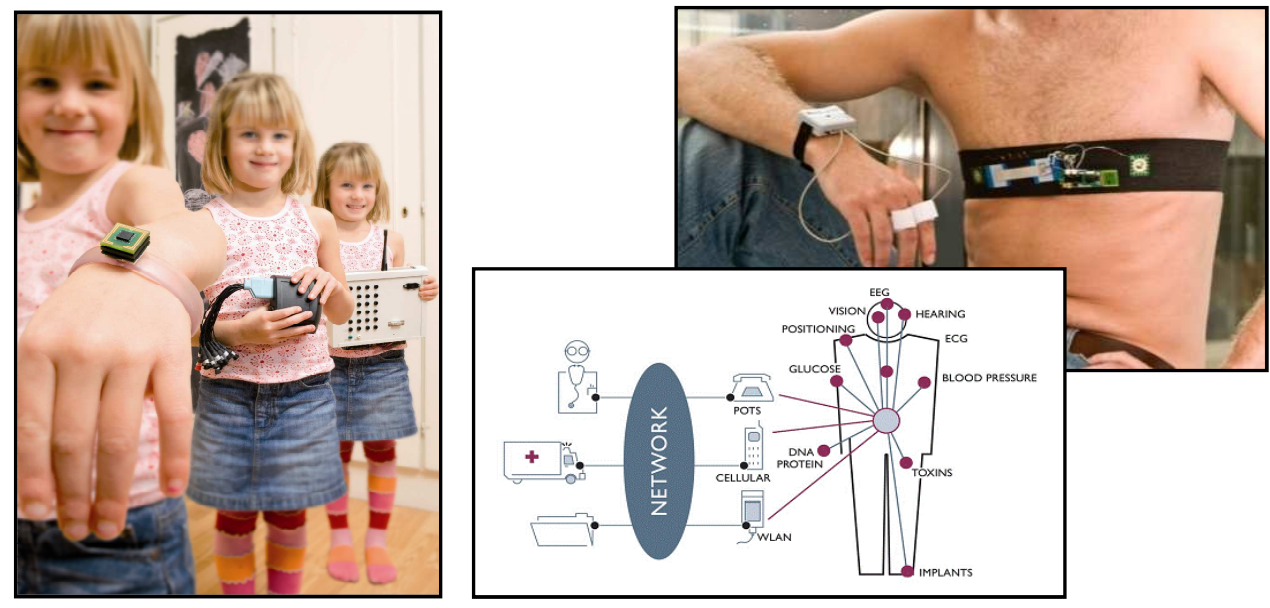

Wearable electronics Snowboard jacket with MP3Bluetooth module

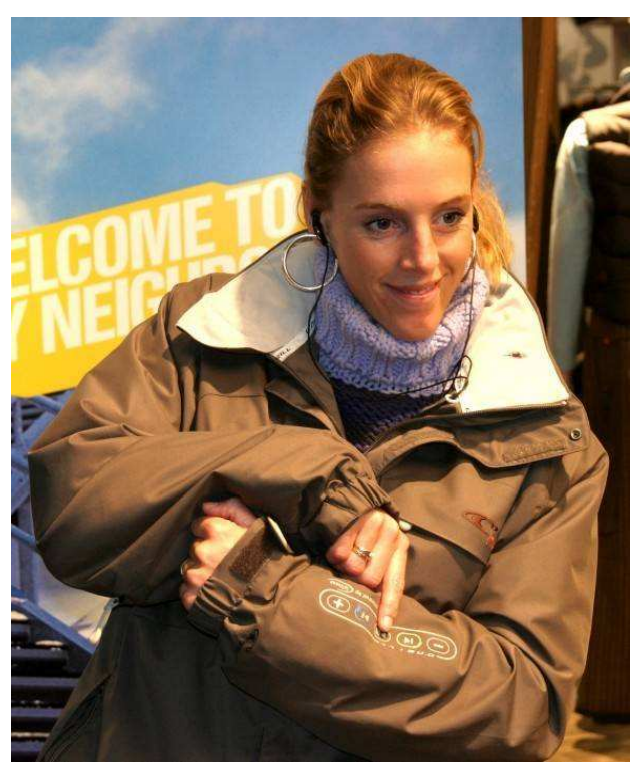

- High-end snowboard jacket with integrated docking station for MP3-Bluetooth module

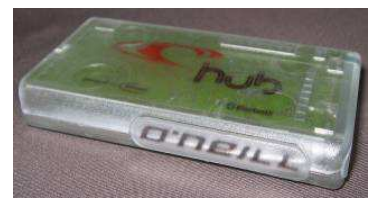

C. Claeys, H. De Man IMEC \& W. Weber, Infineon and Upkar Dhaliwal 


\section{Conclusions and Observations}

- RF technologies must provide RF performance at the lowest cost for today's volume markets.

- Si RF CMOS and SiGe are displacing GaAs from some high volume market segments from $800 \mathrm{MHz}$ through to $100 \mathrm{GHz}$.

- Mask \& design costs remain significant for RF CMOS and SiGe

- these technologies are more suited to very high volume applications, such as WLAN, where they can be highly costeffective. GaAs remains competitive in lower volumes.

- RF SOI is well suited to low power RF and provides easy mixed signal integration at lower cost.

- Trend towards higher levels of integration continues with reduced cost/function at both chip level and module assembly:

- Multi-level RFIC Chip, multi-chip, chip on chip, PoP, PiP. 


\section{Conclusions and Observations}

- GaAs remains competitive for power, switching, high performance and millimetre-wave applications

- high yields and falling costs have increased its competitive position

- ideal for product areas with rapid churn or limited volume runs.

-... and GaAs will remain the most cost effective solution for high power, high frequency applications.

- LDMOS continues to dominate wireless infrastructure with costs falling below $\$ 1 / \mathrm{W}$.

- Impressive GaN performance will compete with lower cost GaAs power FETs and with LDMOS for WI in due course

- The potential for integrating compound semiconductors and silicon technologies on Si substrates has already been demonstrated - this could delivery the optimal solution! 


\section{Acknowledgments}

- WIN Semiconductors, John Atherton, Bob Donahue

- Triquint, Glen Riley, Mike Peters

- Freescale, John Wood, Wayne Burger

- Sony Semiconductor, Chris Clifton and Kamegaya-san

- Mitsubishi Electric Corp., Noriharu Suematsu

- ADI, Wolfgang Bősch

- IMEC, Cor Claeys

- Filtronic, Hemant Mardia

- Upkar Dhaliwal 